Revised Manuscript to

Advances in Structural Engineering - An International Journal

(Special Issue)

Prediction of Punching Shear Failure Behaviour of Slab-Edge

Column Connections with Varying Opening and Column

Parameters

by

Hong Guan

July 2007 


\title{
Prediction of Punching Shear Failure Behaviour of Slab-Edge Column Connections with Varying Opening and Column Parameters
}

\author{
Hong Guan* \\ Griffith School of Engineering, Griffith University Gold Coast Campus, Queensland 4222, Australia
}

\begin{abstract}
A numerical analysis using the non-linear Layered Finite Element Method (LFEM) is undertaken to predict the effect of openings on punching shear failure behaviour of slabcolumn connections with shear stud reinforcement (SSR). In all, twenty one (21) models are examined through six parametric studies including varying the opening size and location and varying the column aspect ratio. The numerical results covering the load-deflection response, ultimate shear strength, deformation and crack pattern are evaluated in some detail. Where applicable the predicted ultimate shear strengths are compared to the experimental results. Also included in the comparison are the empirical predictions recommended by the Standards Association of Australia and the American Concrete Institute. This investigation is an important step towards the determination of the size and location of opening and the size of column for optimum structural performance of flat plate systems.
\end{abstract}

Key words: Flat slab-column connections, openings, failure analysis, parametric study

\footnotetext{
* Corresponding author. Tel: +61-7-5552-8708; fax: +61-7-5552 8065

E-mail address: H.Guan@griffith.edu.au
} 


\section{Introduction}

Reinforced concrete flat plate floor system is a widely used construction method in modern structures, in particular residential buildings and car parks. This is due to the many advantages that this type of system offers, such as reduced storey height, simplified formwork, ease of reinforcement placement, lower construction costs and an aesthetically pleasing appearance. However this system has a major and critical disadvantage in that it has a tendency to fail, due to brittle punching shear at the slab-column connections, at a lower load well below the flexural capacity of the slab. This is particularly true for the area in the close vicinity of edge and corner column connections where large concentrated transverse shear force and unbalanced moments exist.

In flat plate floor systems there is often a need to construct openings in the vicinity of columns. The openings are required mainly for sanitary reasons, ventilation, heating, air conditioning and electrical ducts. The existence of the opening takes away part of the volume of concrete responsible for resisting shear force and unbalanced moment, which in turn further reduces the punching shear capacity of the slab-column connection. The connection is therefore more vulnerable to brittle punching shear failure. The connection can however be strengthened by properly placing and anchoring shear stud reinforcement (SSR) thereby providing sufficient ductility.

Over the past 100 years only a moderate amount of research has been conducted on punching shear strength of flat reinforced concrete slabs with openings in the vicinity of columns, in comparison with other subject matters in structural engineering. This is reflected in the codes of practice covering the design of such structural systems where the conservative nature of code predictions has been widely recognised (El-Salakawy et al. 2000). Moe (1961) 
conducted an investigation focused on the failure of reinforced concrete slabs and footings in shear, where a wide range of experiments were conducted on a variety of different slabs with openings adjacent to the columns. Hognestad et al. (1964) and Mowrer and Vanderbilt (1967) carried out further laboratory tests on slab-interior column connections with openings with particular emphasis on lightweight aggregate concrete slabs, and Roll et al. (1971), on perforated concrete slabs. Not until the mid 90's that studies on the punching shear behaviour of slab-column connections with openings have regained researchers' attention. Over the last decade various laboratory investigations have been conducted. These investigations include openings in the vicinity of square edge columns (El-Salakawy et al. 2000) and openings adjacent to square and rectangular interior columns (Gomes and Silva 2003; Irawan et al. 2003). The effects of SSR were also examined in some of these studies.

Needless to say, laboratory tests are labour-intensive, time-consuming and costly. On the other hand, various empirical and code methods, based heavily on model test results, inevitably involve gross approximations which are not always reliable and, by nature, their scope of applications is limited. Non-linear finite element analysis, however, provides an effective method by which structures can be analysed to progressive failure. It is evident that non-linear analysis of concrete structures has become increasingly important and useful in recent years. For flat plates and slabs, the punching shear failure behaviour has been investigated extensively using special purpose finite element analysis packages where concrete and reinforcing bars are modelled by three-dimensional brick elements with embedded bar elements (e.g. Staller 2001; Ožbolt and Vocke 2001). An efficient and inexpensive layered finite element method has also been developed to model punching shear in flat plates, slabs and slab-column connections (Loo and Guan 1997; Guan and Loo 1997; Polak 1998a and b, Polak 2005), where shell elements are used encompassing concrete and 
smeared steel layers. In these publications it has been shown that shell finite elements can be successfully used in the analyses of slabs and with proper finite element and material formulations they can detect both flexural and punching shear failure modes. Limited work has been done in the punching shear analysis of slab-column connections with shear reinforcement (Polak 1998a and b; Guan and Loo 2003; Polak 2005) and little analytical work has been published dealing with such connections with both openings and SSR (Guan and Polak 2007). Nevertheless, the success of these studies and the high correlation between the numerical and experimental data resulted in the opportunity to extend the research into some detailed parametric studies for the slab-column connections with openings.

The objective of this study is to investigate the effect of varying opening and column parameters on punching shear failure behaviour of slab-column connections with SSR. A numerical analysis using the non-linear Layered Finite Element Method (LFEM) (Guan and Loo 1997) is undertaken to predict this behaviour. In all, twenty one (21) models are investigated through six parametric studies including varying the opening size and location as well as varying the column aspect ratio. The numerical results covering the load-deflection response, ultimate shear strength, deformation and crack pattern are examined. Where applicable the predicted ultimate shear strengths are compared to the experimental results. Also included in the comparison are the empirical predictions recommended by the Standards Association of Australia AS3600 (2001) and the American Concrete Institute ACI318 (2005). The numerical studies confirm the accuracy, effectiveness and reliability of the LFEM in predicting the punching shear failure behaviour of slab-column connections with openings and SSR. 


\section{Layered Finite Element Formulation}

Punching shear failure at flat slab-column connections has a distinct three-dimensional feature. The non-linear Layered Finite Element Method (LFEM) (Guan and Loo 1997; Loo and Guan 1997) was developed to encompass three-dimensional (in-plane and out-of-plane) stress components in its finite element formulation, thereby capable of analysing both flexural and transverse (punching) shear cracking up to failure.

\subsection{Degenerate Shell Element}

Figure 1 shows an 8-node degenerate shell element. The Mindlin plate hypothesis is used to derive such an element from three-dimensional elasticity. Two primary assumptions are adopted: 1) lines normal to mid-surface before deformation remain straight but not necessarily normal after deformations, and 2) normal stress in the transverse direction is equal to zero $\left(\sigma_{z}=0\right)$. These assumptions allow to formulate elements where each nodal point located on the mid-reference surface has five degrees of freedom viz the in-plane displacements, $u$ and $v$, transverse displacement $w$ and two independent bending rotations about the $x$ and $y$ axes, i.e. $\theta_{y}$ and $\theta_{x}$ respectively. The transverse shear deformations are taken into account in the deformation field because the rotations and displacements are uncoupled.

The fundamental principle of the LFEM is that the reinforced concrete element being analysed is subdivided into a number of discrete shell elements each contains a number of concrete layers of varying but uniform thickness. The layer thickness gradually reduces from the mid-s of the element towards the surfaces in order to provide a more detailed account of the extensive cracking close to the bottom and top surfaces. The layers are assumed to be 
fully bonded together. The concrete properties are individually specified over the thickness for each layer.

The bottom and top layers of flexural reinforcing mesh are represented by smeared layers of equivalent thickness and having directions in accordance with those of steel bars. Through the perfect bond, it is assumed that transverse reinforcement undergoes strain corresponding to its direction (for typical reinforcement normal to the plate surface, e.g. shear stud, the strain is $\varepsilon_{\mathrm{z}}$ ). Transverse reinforcement is smeared through the concrete element. Its contribution to the total material matrix is discussed in Section 2.3.

Each layer contains Gauss points on its mid-surface. The stresses within each layer are computed at these points and are assumed to be constant over the layer thickness. These lead to a stepwise approximation of the stress distribution over the element thickness, as also shown in Figure 1. To account for the mechanical change of the materials throughout the incremental loading process, cracking and nonlinear material response are traced layer by layer.

\subsection{Constitutive Model for Concrete}

In the LFEM, concrete failure is identified as a result of either tension cracking or plastic yielding (crushing). A three-dimensional stress state is considered in the model. According to the Mindlin plate assumption, $\sigma_{z}=0$ at the global, element level, as is required for degeneration from the three-dimensional to the shell element. Figure 2(a) depicts the onedimensional representation of the constitutive model for concrete in both tension and 
compression. The constitutive equation for isotropic material, in the material coordinate system ( $\left.x^{\prime} y^{\prime} z\right)$, can be expressed as

$$
d\{\sigma\}=\left[\overline{\overline{\boldsymbol{D}}}_{c}\right] d\{\boldsymbol{\varepsilon}\}
$$

where the three-dimensional stress and strain components are respectively $\{\sigma\}=\left\{\sigma_{x}, \sigma_{y}, \sigma_{z}, \tau_{x y}, \tau_{x z}, \tau_{y z}\right\}$ and $\{\varepsilon\}=\left\{\varepsilon_{x}, \varepsilon_{y}, \varepsilon_{z}, \gamma_{x y}, \gamma_{x z}, \gamma_{y z}\right\}$. Due to the assumption of $\sigma_{z}=0$, each element has five non-zero stresses $\left(\sigma_{x}, \sigma_{y}, \tau_{x y}, \tau_{x z}, \tau_{y z}\right)$ and five independent strains $\left(\varepsilon_{x}, \varepsilon_{y}, \gamma_{x y}, \gamma_{x z}, \gamma_{y z}\right)$. The transverse strain $\varepsilon_{z}$ can be determined from equilibrium with imposed $\sigma_{z}=0$ and is a function of the five independent strains. With all the strain components, the principal strains and their corresponding directions can be calculated, based on which the principal stresses and directions can be determined using appropriate constitutive models for concrete as described below.

The material matrix in Eq. (1) is

$$
\left[\overline{\overline{\boldsymbol{D}}}_{c}\right]=\left[\begin{array}{cccccc}
K+\frac{4}{3} G & K-\frac{2}{3} G & K-\frac{2}{3} G & 0 & 0 & 0 \\
& K+\frac{4}{3} G & K-\frac{2}{3} G & 0 & 0 & 0 \\
& & K+\frac{4}{3} G & 0 & 0 & 0 \\
& & & G & 0 & 0 \\
& \text { Symm } & & & G & 0 \\
& & & & & G
\end{array}\right]
$$


in which $K\left(=\frac{E}{3(1-2 v)}\right)$ and $G\left(=\frac{E}{2(1+v)}\right)$ are the bulk and shear moduli, respectively. $E$ and $v$ are respectively the modulus of elasticity and Poisson's ratio.

An elastic brittle fracture behaviour is assumed for concrete in tension. Cracks are assumed to form in the plane perpendicular to the direction of maximum principal tensile stress as soon as this stress reaches the specified concrete tensile strength $f_{t}$. Cracked concrete is treated as an orthotropic material following a smeared crack approach and the tension cutoff representation is utilized. The constitutive equation for cracked concrete is given as

$$
d\{\boldsymbol{\sigma}\}=\left[\overline{\overline{\boldsymbol{D}}}_{c r}\right] d\{\boldsymbol{\varepsilon}\}
$$

where

$$
\left[\overline{\overline{\boldsymbol{D}}}_{c r}\right]=\left[\begin{array}{cccccc}
E_{i} & 0 & 0 & 0 & 0 & 0 \\
& E_{(22)} & E_{(23)} & 0 & 0 & 0 \\
& & E_{3} & 0 & 0 & 0 \\
& & & G_{12}^{c} & 0 & 0 \\
& \text { Symm } & & & G_{13}^{c} & 0 \\
& & & & & G_{23}^{c}
\end{array}\right]
$$

When concrete cracks in one direction, $E_{(22)}=E_{2}$ and $E_{(23)}=v \sqrt{E_{2} E_{3}} /\left(1-v-2 v^{2}\right)$; when concrete cracks in both directions 1 and $2, E_{(22)}=E_{i}$ and $E_{(23)}=0$. Here $E_{2}$ and $E_{3}$ are the elastic moduli of concrete in directions 2 and 3 respectively. $G_{12}^{c}, G_{13}^{c}$ and $G_{23}^{c}$ are the reduced shear moduli for cracked concrete corresponding to the principal axes 1,2 and $3 . E_{i}$ is the fictitious modulus of elasticity when the tension stiffening effect, as a result of the bond mechanisms, is taken into consideration. This effect assumes a gradual release of the concrete stress component normal to the cracked plane (Hinton and Owen 1984). This is illustrated in 
Figure 2(a) as a descending branch of the stress-strain curve in the tension domain. Also depicted in the figure is the process of loading and unloading of cracked concrete. This process is assumed to follow the linear behaviour with $E_{i}$ given as

$$
E_{i}=\frac{\alpha_{t} f_{t}\left(1-\frac{\varepsilon_{i}}{\varepsilon_{m}}\right)}{\varepsilon_{i}} \quad\left(\varepsilon_{t} \leq \varepsilon_{i} \leq \varepsilon_{m}\right)
$$

where $\alpha_{t}$ and $\varepsilon_{m}$ are the tension stiffening parameters as shown in Figure 2(a), and $\varepsilon_{i}$ is the maximum value reached by the tensile strain at the point currently under consideration. Certain assumptions exist in the model, in particular the tension stiffening parameters which are determined based on the experimental measurements of concrete and the arrangement of steel. The effect of variations in steel arrangement can be captured by having refined meshes for dense areas of reinforcing steels. The influence of different tension stiffening parameters in Eq. (5) on the predictions of punching shear behaviour has been examined by Polak (2005) where $\alpha_{t}=0.6$ and $\varepsilon_{m}=0.002$ were suggested as the values that produce best predictions and thus they are also used in the present study.

For cracked concrete, the amount of shear carried by aggregate interlock decreases with the crack width which can be represented by the principal tensile strain. According to Hinton and Owen (1984), the shear moduli can be assumed to degrade linearly with the increase in principal tensile strains. For concrete cracked in the direction 1 only,

$$
\begin{aligned}
& G_{12}^{c}=G_{13}^{c}=0.25 G\left(1-\frac{\varepsilon_{1}}{0.004}\right) \text { if } \varepsilon_{1}<0.004 ; G_{12}^{c}=G_{13}^{c}=0 \text { otherwise } \\
& G_{23}^{c}=\frac{5}{6} G
\end{aligned}
$$


where $G$ is the uncracked shear modulus and $\varepsilon_{1}$ is the current principal tensile strain in direction 1. For concrete cracked in both directions 1 and 2,

$$
\begin{aligned}
& G_{13}^{c}=0.25 G\left(1-\frac{\varepsilon_{1}}{0.004}\right) \text { if } \varepsilon_{1}<0.004 ; \quad G_{13}^{c}=0 \text { otherwise } \\
& G_{23}^{c}=0.25 G\left(1-\frac{\varepsilon_{2}}{0.004}\right) \text { if } \varepsilon_{2}<0.004 ; \quad G_{23}^{c}=0 \text { otherwise } \\
& G_{12}^{c}=0.5 G_{13}^{c} \text { if } G_{23}^{c}>G_{13}^{c} ; \quad G_{12}^{c}=0.5 G_{23}^{c} \text { otherwise }
\end{aligned}
$$

where $\varepsilon_{1}$ and $\varepsilon_{2}$ are the principal tensile strains in directions 1 and 2 respectively.

The material matrices for cracked concrete $\left[\overline{\overline{\boldsymbol{D}}}_{c r}\right]$ as given in Eq. (4) must be transformed from the principal (material) axes to the local xyz coordinate system, $\left[\boldsymbol{D}_{c r}\right]$, through the transformation matrix $\left[\boldsymbol{T}_{\varepsilon}\right]$ for strain components.

The compressive behaviour of concrete is modelled using the strain-hardening plasticity approach which determines the boundaries of elastic and plastic regions (when the concrete compressive stress reaches $0.3 f_{c}$ where $f_{c}$ is the compressive strength of concrete) and the progress of damage in the plastic zone. The elasto-plastic constitutive equation based on the flow and hardening rules is expressed as

$$
d\{\boldsymbol{\sigma}\}=\left[\boldsymbol{D}_{e p}\right] d\{\boldsymbol{\varepsilon}\}
$$


where

$$
\left[\boldsymbol{D}_{e p}\right]=\left[\boldsymbol{D}_{c}\right]-\frac{\left[\boldsymbol{D}_{c}\right] \boldsymbol{a} \boldsymbol{a}^{\mathrm{T}}\left[\boldsymbol{D}_{c}\right]^{\mathrm{T}}}{H^{\prime}+\boldsymbol{a}^{\mathrm{T}}\left[\boldsymbol{D}_{c}\right]^{\mathrm{T}} \boldsymbol{a}}
$$

and

$$
\left[\boldsymbol{D}_{c}\right]=\left[\boldsymbol{T}_{\varepsilon^{\prime}}\right]^{\mathrm{T}}\left[\overline{\overline{\boldsymbol{D}}}_{c}\right]\left[\boldsymbol{T}_{\varepsilon^{\prime}}\right]
$$

if the principal axes do not coincide with the local reference axes $x, y$ and $z$. In Eq. (9), $\boldsymbol{a}$ is the flow vector and $H^{\prime}$ is the hardening parameter associated with the expansion of the yield surface.

When the compression type of failure transpires in concrete (the ultimate strain $\varepsilon_{u}$ is reached), some but not all strength and rigidity of the material is lost. Hence the material matrix for crushed concrete takes a similar form as Eq. (2) by considering only the contribution of the bulk modulus $K$. Or,

$$
\left[\boldsymbol{D}_{\text {crs }}\right]=\left[\begin{array}{cccccc}
K & K & K & 0 & 0 & 0 \\
& K & K & 0 & 0 & 0 \\
& & K & 0 & 0 & 0 \\
& & & 0 & 0 & 0 \\
& S y m m & & & 0 & 0 \\
& & & & & 0
\end{array}\right]
$$

Numerical modelling of either cracking or crushing of concrete involves the modification of material stiffness and partial or full release of the appropriate stresses in the fractured elements. 


\subsection{Constitutive Model for Steel}

The reinforcing steel is assumed to be uniaxial elastic-plastic material. A trilinear idealisation of steel is shown in Figure 2(b). When the stress in the direction of the reinforcement exceeds $80 \%$ of the yield strength $f_{y}$, Young's modulus of steel $E_{s}$ is replaced by $E_{s 1}$; and if $f_{y}$ is reached, the steel is assumed to have yielded and $E_{s 2}$ is then assumed. The values of $E_{s 1}$ and $E_{s 2}$ are taken based on the experimental stress-strain measurement of steel bars. The steel bars at a given level in an element are modelled as a smeared layer of equivalent thickness. For a steel layer, the constitutive equation is given as

$$
d\{\boldsymbol{\sigma}\}=\left[\overline{\overline{\boldsymbol{D}}}_{s}\right] d\{\boldsymbol{\varepsilon}\}
$$

where the material matrix in the material coordinate system is

$$
\left[\overline{\overline{\boldsymbol{D}}}_{\mathrm{s}}\right]=\left[\begin{array}{cccccc}
\rho_{s} E_{s} & 0 & 0 & 0 & 0 & 0 \\
& 0 & 0 & 0 & 0 & 0 \\
& & 0 & 0 & 0 & 0 \\
& & & 0 & 0 & 0 \\
& \text { Symm } & & & 0 & 0 \\
& & & & & 0
\end{array}\right]
$$

in which $\rho_{s}(s=x, y)$ is the reinforcement ratio (in the in-plane $x$ - and $y$-directions) for a steel layer. If the directions of the steel bars do not coincide with the $x$-axis, [ $\left.\overline{\overline{\boldsymbol{D}}}_{s}\right]$ must also be transformed into the local coordinate system, $\left[\boldsymbol{D}_{s}\right]$. 


\subsection{Total Material Matrix}

The total material matrix $[\overline{\boldsymbol{D}}]$ containing the contributions of concrete and steel can be determined for each element and the stiffness matrix for the corresponding element can be evaluated using the Gaussian integration technique with the selective integration rule. $[\overline{\mathbf{D}}]$ is expressed as

$$
[\overline{\boldsymbol{D}}]=\sum_{i=1}^{n_{c}}\left[\overline{\boldsymbol{D}}_{c}\right]+\sum_{i=1}^{n_{s}}\left[\boldsymbol{D}_{s}\right]
$$

where $\left[\overline{\boldsymbol{D}}_{c}\right]$ is in the form of $\left[\boldsymbol{D}_{c r}\right],\left[\boldsymbol{D}_{e p}\right]$ or $\left[\boldsymbol{D}_{c r s}\right]$ depending on the current stress condition; $n_{c}$ and $n_{s}$ are the total numbers of concrete and steel layers, respectively (see Figure 1). Note that $[\overline{\boldsymbol{D}}]$ is of a standard size $6 \times 6$. Considering the conventional plane stress assumption $\left(\sigma_{z}=0\right),[\overline{\boldsymbol{D}}]$ must be condensed into $5 \times 5$ in size which results in a diagonal term containing $\rho_{z} E_{s}$. This implies that the effect of the out-of-plane (transverse) reinforcement (in the $z$-direction) can be included by adding its contributions to the concrete material matrix which corresponds to the normal strain in the transverse direction $\left(\varepsilon_{z}\right)$. The shear studs are included in the model by treating them as transverse reinforcement where $\rho_{z}=\rho_{s t}$ and $E_{s}=$ $f_{s t} / \varepsilon_{s t}$, in which $\rho_{s t}$ is the average transverse reinforcement ratio over an element, $f_{s t}$ is the yield strength of transverse reinforcement and $\varepsilon_{s t}$ is the strain in the direction of the reinforcement.

Finally the structural stiffness matrix is assembled using the standard procedure. The Newton-Raphson method, an incremental and iterative procedure, is used to obtain the nonlinear solution due to both material and geometric nonlinearities in slab-column 
connection problems. The reliability of the abovementioned material constitutive model has been demonstrated in various publications (Loo and Guan 1997; Guan and Loo 1997, 2003; Guan and Polak 2007).

\section{The Model Layout}

In this study, twenty one (21) models of slab-column connection are investigated through six parametric studies (PS) covering variations of the opening size and location as well as the column aspect ratio. The models are generated based on experimental specimens (representing edge columns connected to a slab bounded by the theoretical contraflexure lines around the column) tested by El-Salakawy et al. (2000). All the models are similar in terms of the general layout such as slab size and thickness, column height and location, the overall arrangement of flexural reinforcement, and the restraint and loading conditions. Figure 3 shows a typical slab-column connection model where the dimension of the slab is $1540 \times 1020 \times 120 \mathrm{~mm}$ with an average effective depth of the slab $d=90 \mathrm{~mm}$. The column cross section is $250 \times 250 \mathrm{~mm}$ and its height above and below the slab is $700 \mathrm{~mm}$. In all parametric studies, the column is loaded in the same way as illustrated in Figure 3(a), where a vertical force, $V$ (replicating the concentrated shear force) and two horizontal forces, $H$ (creating the unbalanced bending moment) are applied through the column stub. The vertical force through the centre of the column also helps facilitate the measurement of the punching shear strength $\left(V_{u}\right)$ of the connection, which equals the applied vertical force $V$ at the ultimate stage. Based on the analysis of a typical floor system subjected to a factored gravity load, the ratio between the unbalanced moment $M$ (produced by $H$ ) and the vertical force $V, M / V$ was calculated as 0.3m (El-Salakawy et al. 2000). In the numerical analysis, the $M$ and $V$ are applied in increments retaining the same $M / V$ ratio. As indicated in Figure 3(b), all models are simply 
supported along the three sides with the slab edge being free. Corners of the slabs are restrained from lifting.

Table 1 summaries the details of the models for six parametric studies (PS) including a description of the notations used. The corresponding model layouts are presented in Figure 4. The variables in the PS are:

(1) PS-1: varying opening size (both $x$ - and $y$-directions);

(2) PS-2: varying opening aspect ratio ( $x$-direction);

(3) PS-3: varying opening aspect ratio (y-direction);

(4) PS-4: varying opening location from front face of column;

(5) PS-5: varying column aspect ratio ( $x$-direction); and

(6) PS-6: varying column aspect ratio (y-direction).

where the $x$ - and $y$-directions are indicated in Figure 3(b).

The flexural reinforcement used for all the models is derived from the reinforcement layouts adopted in the laboratory test (El-Salakawy et al. 2000). The slab is reinforced with both tension (M10@220mm in the $x$ - and M10@154mm in the $y$-directions, respectively) and compression layers (M5@135mm in the $x$ - and M5@135mm in the $y$-directions, respectively) of steel mesh, with a slightly higher concentration of steel on the tension side. The reinforcement spacing is smaller in the column strips than other areas of the slab. The average reinforcement ratios are 0.0075 and 0.0045 respectively for both directions of steel in tension and compression zones. Furthermore, for slabs with an opening, the sides of the opening are provided with additional reinforcement to replace the bars that are interrupted by the opening. For all models, the column is heavily over-reinforced with M25 longitudinal bars and M8 ties 
to prevent premature failure of the slab-column connection by the column failing in bending or compression (El-Salakawy et al. 2000).

The shear studs used in the parametric studies are also based on those specified by ElSalakawy et al. (2000). Each single shear stud rail consists of six studs of $75 \mathrm{~mm}$ in height with a stem diameter of $9.5 \mathrm{~mm}$, while the head of the stud is $30 \mathrm{~mm}$ in diameter with a $5.3 \mathrm{~mm}$ thickness. The six studs are welded to a $360 \times 25.4 \times 4.8 \mathrm{~mm}$ rail and positioned accordingly within the slab as shown in Figure 3(c). Details of shear studs can be found elsewhere (Guan and Polak 2007). Each model consists of six rows of shear studs arranged around the column in a similar manner as shown in Figure 3(c), except for PS-6 in which the two rows of shear studs in the $x$-direction are not considered due to the opening impairing the positioning of any subsequent shear studs in this direction. In addition, due to the variations of the opening and column sizes, often the shear stud position requires slight modification from that shown in Figure 3(c) to compensate for the variables in question.

The concrete compressive strength of all the models are taken as $32 \mathrm{MPa}$ which is identical to that of the control specimen XXX-R without an opening, tested by El-Salakawy et al. (2000). Note that models XXXX and C60F0 studied herein are equivalent to the test specimens XXX-R and SF0-R respectively. The accuracy and reliability of the numerical models are calibrated through comparison with the available test results. Note also that amongst all the models, C80F0, Ox100 and Oy100 are equivalent and C80F1 and Cx100 are also equivalent. This makes a total of 21 different models for the analysis. 


\section{Parametric Studies}

Six parametric studies (PS) are carried out to examine the effect of varying opening size and location as well as varying column aspect ratio on the ultimate behaviour of the slabcolumn connections. In this study the opening sizes are considered not to exceed $80 \%$ of the column size. This is because an opening of the size of a column is not recommended in design (El-Salakawy et al. 2000). In all parametric studies, the load-deflection response, the punching shear strength $V_{u}$, the deflected shape as well as the crack pattern are examined in some detail. A symmetrical half of each model is analysed which is subdivided into approximately 150-200 elements based on a convergence study. Typical finite element mesh designs are presented in Figure 5. The column region is modelled using the same 8-node shell elements with much higher stiffness to account for the longitudinal steels and closed ties. Each element is comprised of eight concrete layers of reduced thickness from the shell midsurface and four steel layers of equivalent thickness representing the tension and compression reinforcement meshes.

To better simulate the concentrated effect of the shear studs, the element meshes at the stud locations are made relatively narrow (same as the width of stud rail, see Figure 5) and all the studs on the same rail are located at the centre line of the elements covering the stud rail. The corresponding equivalent (smearing) stud ratios $\rho_{\text {st }}$ for these elements are calculated. The presence of the anchor head and the rail, located near the top and bottom layers, are also considered in calculating $\rho_{\text {st }}$ for the concerned layers. Hence different layer may have different $\rho_{\text {st }}$ depending on the relative position of the stud rail in the transverse direction. 


\subsection{PS-1: Varying Opening Size (both $x$ - and y-directions)}

A total of five different models as shown in Figure 4(a) are analysed. The first model $\mathrm{XXXX}$ is the control model without an opening. The remaining models C40F0, C50F0, C60F0 and C80F0 each has an opening located at the centre of the front column face. Keeping the aspect ratio as one, the sizes of the opening $(O)$ vary from $40 \%$ to $80 \%$ of the column size ( $C=250 \mathrm{~mm})$, as also detailed in Table 1 . It can be observed from the mesh designs for C40F0 and C60F0 (Figure 5) that the region representing additional reinforcement around the opening varies proportionally with the opening size to the extent that the extra steel extending past the opening is equal in length to that of the side of the opening.

Figure 6 illustrates the failure characteristics of selected models in PS-1. Figure 6(a) presents the load-deflection responses predicted by the LFEM as well as the experimental data for XXXX and C60F0. It is evident that the yielding point for all the models is at approximately $50 \mathrm{kN}$ which corresponds well to the experimental observation where the formation of flexural cracks on the tensile surface was initiated at the vertical load of 49 to 55 kN (El-Salakawy et al. 2000). The comparisons suggest that the stiffness and punching shear capacity $\left(V_{u}\right)$ (as summarised in Table 2) of the connection decreases with enlarged size of opening thereby increasing the deflection at the same load level. The results also indicate that the slab with the largest opening (C80F0) does not necessarily have the greatest deflection at failure. Attention should be drawn towards the fact that the deflections tend to increase rapidly as the model approaches its failure load. The effects of varying parameters on $V_{u}$ (Table 2) are further discussed in Section 5. 
Figure 6(b) shows the predicted deflected shapes for XXXX and C80F0 where the maximum vertical deflection occurs at the column stub. This is due to the experimental setup where the slab was simply supported along the contraflexure lines while the loaded column was free to displace vertically (see Figure 3). Figure 6(c) presents the LFEM predicted crack pattern for C60F0 on its tension side. Note that the solid lines in the figure indicate only the crack direction at specific Gauss points but do not offer information on crack length and width. It can be seen that cracks develop around the corners of the opening and propagate at approximately 45 with respect to the edges of the slab. This agrees well with the experimental observation of an equivalent specimen SF0-R (El-Salakawy et al. 2000).

It is also noticed in Figure 6(c) that a larger number of cracks spread over a greater area as predicted by the LFEM in comparison with the experimental observation. This is because in the LFEM a crack is displayed at a Gauss point at which the tensile strength of concrete $\left(f_{t}\right)$ is exceeded regardless of the length or width of the crack. In the experiment however, smaller cracks are either not visible or merged together forming a larger and more localized crack. Nevertheless together with the deflected shape and load-deflection response, the punching shear failure behaviour of the slab-column connections can be simulated satisfactorily by the LFEM.

4.2. PS-2: Varying Opening Aspect Ratio (x-direction) and PS-3: Varying Opening Aspect Ratio (y-direction)

Varying the opening size in the $x$-direction $\left(O_{x}\right)$ while keeping that in the $y$-direction $\left(O_{y}\right.$ $=200 \mathrm{~mm}$ ) constant results in four models for PS-2 with varying opening aspect ratio (Ox37, Ox50, Ox75 and Ox100 with $O_{x} / O_{y}=0.375,0.5,0.75$ and 1.0 respectively). On the other 
hand, PS-3 consists of four models with varying the opening size in the $y$-direction $\left(O_{y}\right)$. They are Oy37, Oy50, Oy75 and Oy100 with $O_{y} / O_{x}=0.375,0.5,0.75$ and 1.0 respectively. The model details are given in Table 1 and Figure 4 . The opening is positioned directly at the front face of the column. The load-deflection responses and failure characteristics of the models are similar to those discussed for PS-1. As evident in Table 2, the ultimate shear strength $\left(V_{u}\right)$ decreases as the opening aspect ratio (with respect to either $x$ - and $y$-direction) increases.

\subsection{PS-4: Varying Opening Location from Front Face of Column}

Four models viz C80F0, C80F1, C80F2 and C80F3 are considered where the opening size remains constant $(200 \mathrm{~mm})$ at $80 \%$ of the column size $(\mathrm{C}=250 \mathrm{~mm})$. The distance ' $D_{o}$ ' between the opening and the column front face varies from 0 to $270 \mathrm{~mm}$ at $90 \mathrm{~mm}$ interval, resulting in $D_{o} / d=0,1,2,3$ for the four models (see Table 1 and Figure 4). While similar load-deflection responses and failure characteristics are identified, both the ultimate shear strength $\left(V_{u}\right)$ (see Table 2) and the maximum vertical deflection increase as the opening is moved further away from the column face.

4.4. PS-5: Varying Column Aspect Ratio (x-direction) and PS-6: Varying Column Aspect Ratio (y-direction)

In PS-5 and PS-6, both the opening size $(200 \mathrm{~mm})$ and location (90mm away from the front face of the column) remain constant. The column aspect ratio, $C_{x} / C_{y}$, varies from 0.3 , 0.6, 0.8 to 1.0 for four models in PS-5 and $C_{y} / C_{x}$, varies identically, for four models in PS-6. It is found that varying the column aspect ratio with respect to the $x$-direction has little 
influence on the load-deflection responses in particular the ultimate shear strength $\left(V_{u}\right)$ for models in PS-5 (see Table 2). For models in PS-6, on the other hand, an increase in the column aspect ratio with respect to the $y$-direction results in a slight increase in $V_{u}$ (see Table 2). Again the load-deflection responses and failure characteristics of all the models in these two parametric studies are similar to other models.

\section{Comparison of $V_{u}$ Predicted by LFEM and Code Methods}

The predicted punching shear strength results $\left(V_{u}\right)$ for all the models are presented in Table 2. Also included in the table are the measured $V_{u}$ for $\mathrm{XXXX}$ and C60F0 as well as the ratios of the predicted and experimental $V_{u}$, viz 0.94 and 0.92 respectively for the two models. An earlier study (Guan and Polak 2007) also showed similar ratios when comparing the predicted and experimental $V_{u}$ for various other test specimens. Although the LFEM appears to slightly underestimate the experimental results, the correlations are considered satisfactory in view of the very complex punching shear failure behaviour and the various assumptions associated with the LFEM.

Table 2 also compares the predicted $V_{u}$ with the empirical predictions recommended by the Standards Association of Australia AS3600 (2001) and the American Concrete Institute ACI318 (2005), as well as the ratios of the LFEM and code predictions. These predictions are also shown diagrammatically in Figure 7. In comparison with the LFEM, both AS3600 and ACI318 underestimate the punching shear strength $V_{u}$. The AS3600 underestimates $V_{u}$ by a minimum of $23.7 \%$ for PS- 6 and a maximum of $32 \%$ for PS-2. The minimum and maximum are respectively 33.3\% for PS-4 and 51.5\% for PS-2 as a result of ACI318 recommendation. In addition, for each parametric study, the AS3600 is superior to the ACI318, having consistently 
smaller mean ratios and standard deviations. The LFEM predictions tend to suggest that the existence of an opening (either square or rectangle), of the size of up to $80 \%$ of the column cross section, does not significantly change the punching shear strength of the slab-column connection. An earlier study (Guan and Polak 2007) demonstrated that there is a significant reduction in ultimate strength if the opening is of a column size. For slab models with a square column (PS-1 to PS-4), the maximum reduction of LFEM predicted $V_{u}$ for the model with an opening as compared to that without an opening is $8.3 \%$. At the same time, both codes predict maximum reductions of $V_{u}$ of approximately $16.7 \%$ (AS3600) and $48.3 \%$ (ACI318) for all models. Similar prediction patterns are also noticed for models with a nonsquare column (PS-5 and PS-6).

Both the AS3600 and AC318 adopt a strategy of removing portion of the critical perimeter depending on the size and location of the opening and the size of the column (see Figure 8). For PS-1 where the opening size increases linearly, the critical shear perimeter, $u$, decreases linearly (Figure 8(a)). Hence as indicated in Figure 7(a), both codes predict linearly reduced $V_{u}$ with increased opening size. When the opening aspect ratio increases linearly with respect to the $x$-direction (PS-2), the overall length of $u$ remains unchanged (Figure 8(a)) thereby resulting in constant predictions of $V_{u}$ by both codes (Figure 7(b)). This implies that both codes do not consider the effect of opening length in the $x$-direction but in reality it does have an effect. The code predictions of $V_{u}$ are linearly reduced (Figure $7(\mathrm{c})$ ) when the opening aspect ratio increases linearly with respect to the $y$-direction (PS-3), because $u$ decreases linearly (Figure 8(a)). In case of PS-4 where the opening moves away from the column face in a linear step, the overall length of $u$ does not increase linearly (Figure 8(a)). Therefore both codes yield increased $V_{u}$ in a nonlinear manner (Figure $7(\mathrm{~d})$ ). When the column aspect ratio increases (with respect to the $x$ - and $y$-directions for PS-5 and PS-6 
respectively), the increase in the overall length $u$ is almost linear (Figure 8(b)). As a result, the increase in $V_{u}$ as predicted by both codes is approximately linear (Figures 7(e) and (f)). Note that the LFEM predictions are more or less linear for all the models and the gradient of variations in $V_{u}$ closely follow that of AS3600 (except for PS-2 and PS-5).

Figure 7 further confirms that the method for accounting of openings in the presented codes (ACI318 in particular) seems to be overly conservative in predicting the strength of slabs with openings and SSR. In view of this, further experimental and theoretical studies should be undertaken to clarify this issue.

\section{Conclusion}

Using the non-linear Layered Finite Element Method (LFEM), six parametric studies are carried out to examine the punching shear failure behaviour of 21 slab-edge column connections with openings and shear stud reinforcement (SSR). The finite element formulation is based on layered shell elements which include shear deformations and consider three-dimensional states of stress within each layer. Appropriate constitutive models for concrete and reinforcement are adopted. The specific impacts of varying opening and column parameters are evaluated through the load-deflection response, the ultimate shear strength, the deflected shape and crack pattern. Comparisons with the available experimental data in the present and earlier studies (Guan and Polak 2007) confirm the accuracy and reliability of the LFEM in replicating the failure behaviour of slab-column connections in practice. This has an important value for practical industrial applications as it shows that the LFEM is an effective tool in global analysis suitable for the design of reinforced concrete slab-column systems with the aim of achieving optimum structural performance. 
The study has resulted in the following findings:

(a) The influence of the opening on the ultimate strength is small when the size of opening is up to $80 \%$ of the column size;

(b) Increasing the size and aspect ratio (in both $x$ - and $y$-directions) of an opening in the vicinity of the front column face slightly decreases the ultimate shear strength of the connection when the opening size is up to $80 \%$ of the column size;

(c) The further the opening from the column, the higher the ultimate strength of the connection (with a slight increase);

(d) Increasing the column aspect ratio (in both $x$ - and $y$-directions) slightly increases the ultimate strength of the connection;

(e) The empirical punching shear strength predictions recommended by the AS3600 and ACI318 are overly conservative.

This study has also demonstrated that much research is needed to refine the empirical formulae used by various national codes of practice in predicting the punching shear strength capacity of slab-column connections. The conservative nature of the codes should be rectified by conducting further experimental and theoretical studies.

\section{References}

American Concrete Institute (ACI). (2005). Building code requirements for reinforced concrete (ACI 318-05) and commentary - ACI318R-05, Detroit, Michigan. 
El-Salakawy, E.F., Polak, M.A. and Soliman, M.H. (2000). "Reinforced concrete slab-column edge connections with shear studs”, Canadian Journal of Civil Engineering, Vol. 27, No. 2, pp. 338-348.

Gomes, R.B. and Silva, J.A. (2003). "Punching shear resistance of reinforced concrete flat slab with openings and rectangular columns”, Proceedings of the Ninth East AsiaPacific Conference on Structural Engineering and Construction, Institut Teknologi Bandung, Bali, Indonesia, December, RCS 231-236.

Guan, H. and Loo, Y.C. (1997). "Flexural and shear failure analysis of reinforced concrete slabs and flat plates”, Advances in Structural Engineering, Vol. 1, No. 1, pp. 71-85.

Guan, H. and Loo, Y.C. (2003). "Failure analysis of column-slab connections with stud shear reinforcement”, Canadian Journal of Civil Engineering, Vol. 30, No. 5, pp. 934-944.

Guan, H. and Polak, M.A. (2007). "Finite Element Studies of RC Slab-Edge Column Connections with Openings”, Canadian Journal of Civil Engineering, Vol. 34, No. 8, pp. 952-965.

Hinton, E., and Owen, D.R.J. 1984. Finite element software for plates and shells. Pineridge Press Limited, Swansea, UK.

Hognestad, E., Elstner, R.C. and Hanson, J.A. (1964). "Shear strength of reinforced structural lightweight aggregate concrete slabs”, ACI Structural Journal, Vol. 61, No. 6, pp. 643656.

Irawan, P., Liew, J.T., Kong, K.L. and Teng, S. (2003). "Punching shear strength of slabcolumn connections with opening and strengthened with shear stud reinforcement”, Proceedings of the Ninth East Asia-Pacific Conference on Structural Engineering and Construction, Institut Teknologi Bandung, Bali, Indonesia, December, RCS 97-102.

Loo, Y.C., and Guan, H. (1997). “Cracking and punching shear failure analysis of RC flat plates.” Journal of Structural Engineering, ASCE, Vol. 123, No. 10, pp. 1321-1330. 
Moe, J. (1961). "Shearing strength of reinforced concrete slabs and footings under concentrated loads”, Development Department Bulletin D47, Portland Cement Association, Skokie, pp. 1-130.

Mowrer, R.D. and Vanderbilt, M.D. (1967). "Shear strength of lightweight aggregate reinforced concrete flat plates”, ACI Structural Journal, Vol. 64, No. 11, pp. 722-729.

Ožbolt, J., and Vocke, H. 2001. Three dimensional numerical analysis of punching failure. fib Bulletin 12, Punching of Structural Concrete Slabs, 71-78.

Polak, M.A. (1998a). "Shear analysis of reinforced concrete shells using degenerate elements”, Computers \& Structures, Vol. 68, No. 1-3, pp. 17-29.

Polak, M.A. (1998b). "Modelling punching shear of RC slabs using layered finite elements”, ACI Structural Journal, Vol. 95, No. 1, pp. 71-80.

Polak, M.A. (2005). "Shell finite element analysis of reinforced concrete plates supported on columns”, Engineering Computation: International Journal of Computer Aided Engineering and Software, Vol. 22, No. 4, pp. 409-428.

Roll, F., Zaidi, S.T.H., Sabnis, G. and Chuang, K. (1971). "Shear resistance of perforated reinforced concrete slabs”, ACI Publication, SP-30, pp. 77-101.

Standards Association of Australia (SAA). (2001). AS3600-2001: Concrete structures, Sydney, Australia.

Staller, M. (2001). “Numerical analysis with the finite element program MARC”, fib Bulletin 12, Punching of Structural Concrete Slabs, pp. 103-109. 


\section{List of Tables}

Table 1. Details of models for parametric studies (PS)

Table 2. Comparison of $V_{u}(\mathrm{kN})$

\section{List of Figures}

Figure 1. 8-node degenerate shell element with concrete and steel layers

Figure 2. Material constitutive model: (a) concrete in compression and tension (onedimensional representation); (b) steel

Figure 3. Typical slab-column connection model (dimensions in mm): (a) elevation; (b) plan view; (c) connection with shear stud and opening

Figure 4. Model layout for parametric studies (PS): (a) Control model and PS-1: varying opening size (both $x$ - and $y$-directions); (b) PS-2: varying opening aspect ratio ( $x$ direction); (c) PS-3: varying opening aspect ratio (y-direction); (d) PS-4: varying opening location from front face of column; (e) PS-5: varying column aspect ratio ( $x$-direction); (f) PS-6: varying column aspect ratio (y-direction)

Figure 5. Mesh design for models in PS-1: (a) C40F0; (b) C60F0

Figure 6. Failure characteristics of models in PS-1: (a) load-deflection response; (b) deflected shape (XXXX and C80F0); (c) crack pattern (C60F0)

Figure 7. Effect of varying parameters on $V_{u}(\mathrm{kN})$ : (a) PS-1; (b) PS-2; (c) PS-3; (d) PS-4; (e) PS-5; (f) PS-6

Figure 8. Critical shear perimeter used in AS3600 and ACI318: (a) varying opening size and location; (b) varying column size 


\section{Notation}

$[\bar{D}]$

$\left[\overline{\overline{\boldsymbol{D}}}_{c}\right],\left[\boldsymbol{D}_{c}\right]$

$\left[\overline{\boldsymbol{D}}_{c}\right]$

$\left[\overline{\overline{\boldsymbol{D}}}_{c r}\right],\left[\boldsymbol{D}_{c r}\right]$

$\left[\boldsymbol{D}_{\text {crs }}\right]$

$\left[\boldsymbol{D}_{e p}\right]$

$\left[\overline{\overline{\boldsymbol{D}}}_{s}\right],\left[\boldsymbol{D}_{s}\right]$

$\left[\boldsymbol{T}_{\mathcal{E}^{\prime}}\right]$

$\{\sigma\},\{\varepsilon\}$

a

C, $O$

$C_{x}, C_{y}, O_{x}, O_{y}$

$D_{o}$

$d$

$E_{1}, E_{2}, E_{3}$

$E_{i}$

$E_{s}, E_{s 1}, E_{\mathrm{s} 2}$

$f_{c}^{\prime}$

$f_{t}$

$f_{y}$
$=$ total material constitutive matrix in local coordinate system

$=$ constitutive matrix for concrete in material and local coordinate systems, respectively

$=$ constitutive matrix for concrete at different stage

$=$ constitutive matrix for cracked concrete in material and local coordinate systems, respectively

$=$ constitutive matrix for crushed concrete

$=$ elasto-plastic constitutive matrix

$=$ constitutive matrix for steel in material and local coordinate systems, respectively

$=$ transformation matrix for strain components

$=$ stress and strain components, respectively

$=$ flow vector

$=$ size of square column and opening, respectively

$=$ size of column and opening in $x$ - and $y$-directions, respectively

$=$ distance of the opening from the column face

$=$ Effective depth of slab

$=$ elastic moduli of concrete in principal directions

$=$ fictitious modulus of elasticity

$=$ Trilinear moduli of steel

$=$ compressive strength of concrete

$=$ tensile strength of concrete

$=$ yield strength of steel 
$f_{s t}$

$G, G_{12}^{c}, G_{13}^{c}, G_{23}^{c}$

$H^{\prime}$

K

M

$n_{c}, n_{s}$

$u$

$u, v, w$

$V, H$

$V_{u}$

$x^{\prime}, y^{\prime}, z^{\prime}$

$x, y, z$

$\alpha_{t}, \varepsilon_{m}$

$\varepsilon_{1}, \varepsilon_{2}$

$\varepsilon_{s t}$

$\varepsilon_{u}$

$\varepsilon_{x}, \varepsilon_{y}, \varepsilon_{z}, \gamma_{x y}, \gamma_{x z}, \gamma_{y z}$

$\sigma_{x}, \sigma_{y}, \sigma_{z}, \tau_{x y}, \tau_{x z}, \tau_{y z}$

$v$

$\rho_{\mathrm{s}}$

$\rho_{s t}$

$\theta_{x}, \theta_{y}$
$=$ yield strength of transverse reinforcement

$=$ shear and reduced shear moduli of uncracked and cracked concrete, respectively

$=$ hardening parameter

$=$ bulk modulus of concrete

$=$ unbalanced moment at slab-column connection

$=$ total numbers of concrete and steel layers, respectively

$=$ critical shear perimeter

$=$ nodal displacements in the $x$-, $y$ - and $z$-directions

$=$ vertical and horizontal forces applied to column stub, respectively

$=$ ultimate shear strength of slab-column connection

$=$ material coordinate system

$=$ local coordinate system

$=$ tension stiffening parameters

$=$ principal tensile strains in directions 1 and 2, respectively

$=$ strain in the direction of reinforcement

$=$ ultimate compressive strain of concrete or ultimate strain of steel

$=$ normal and shear strains in the xyz coordinate system

$=$ normal and shear stresses in the xyz coordinate system

$=$ Poisson's ratio

$=$ reinforcement ratio

$=$ average transverse reinforcement ratio over an the element

$=$ nodal rotations about the $y$ - and $x$-directions, respectively 
Table 1. Details of models for parametric studies (PS)

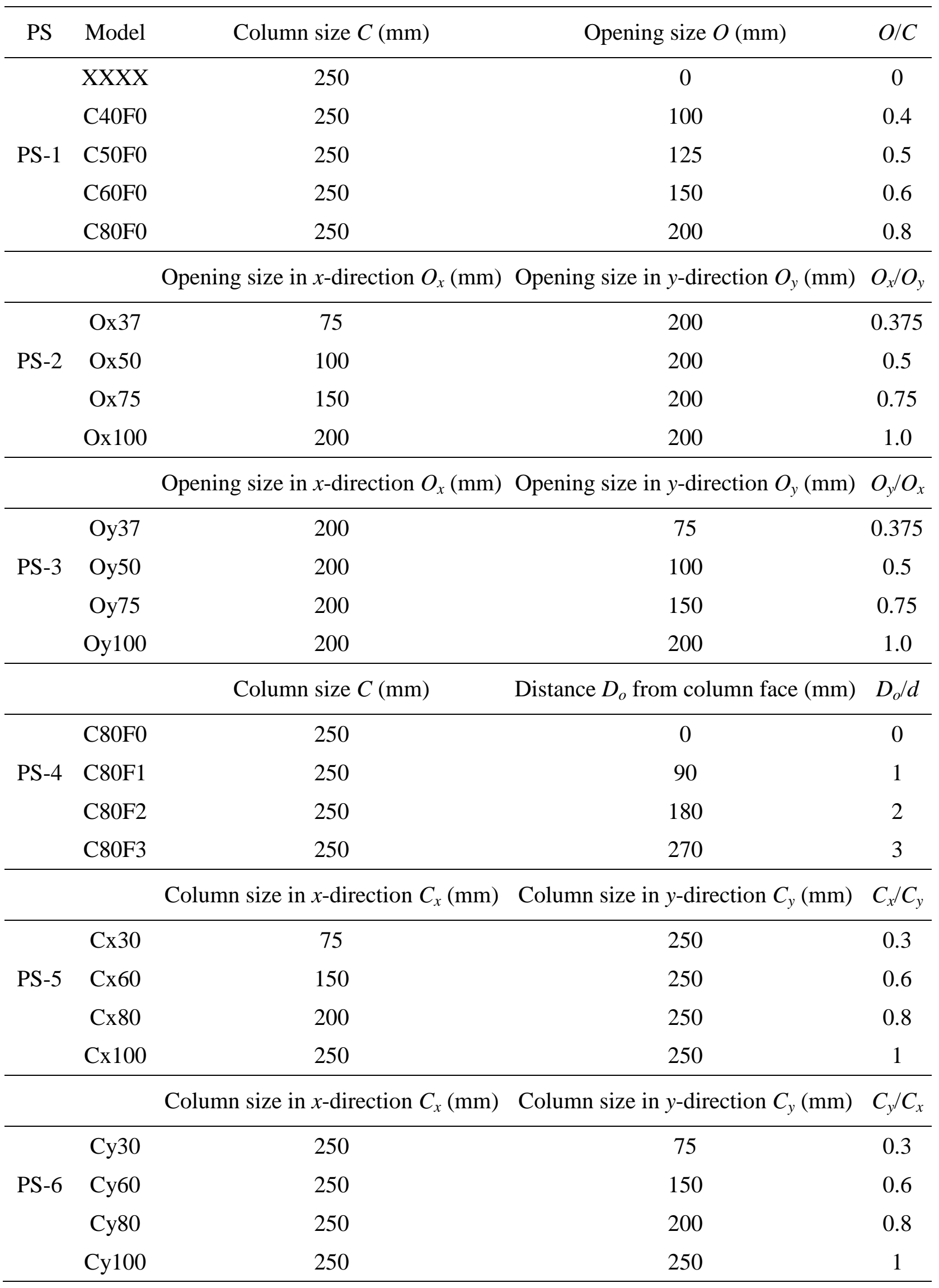


Note: (1) XXXX is the control model;

(2) C-number indicates the percentage size of opening to the column size;

(3) F-number indicates the front face of column and the ratio of distance $D_{o}$ (between the opening and the column face) and the average effective depth of the slab $d$;

(4) $\mathrm{O}_{\mathrm{x}}$-number and $\mathrm{O}_{\mathrm{y}}$-number indicate the opening aspect ratio $O_{x} / O_{y}$ and $O_{y} / O_{x}$, respectively;

(5) $\mathrm{C}_{\mathrm{x}}$-number and $\mathrm{C}_{\mathrm{y}}$-number indicate the column aspect ratio $C_{x} / C_{y}$ and $C_{y} / C_{x}$, respectively. 
Table 2. Comparison of $V_{u}(\mathrm{kN})$

\begin{tabular}{|c|c|c|c|c|c|c|c|c|}
\hline Parametric study & Model & $V_{u, L F E M}$ & $V_{u, A S}$ & $V_{u, A C I}$ & $\frac{V_{u, L F E M}}{V_{u, A S}}$ & $\frac{V_{u, L F E M}}{V_{u, A C I}}$ & $V_{u, E x p}$ & $\frac{V_{u, L F E M}}{V_{u, \text { Exp }}}$ \\
\hline \multirow{7}{*}{ PS-1 } & XXXX & 144 & 113.14 & 129.82 & 1.27 & 1.11 & 154 & 0.94 \\
\hline & C40F0 & 138 & 104.48 & 99.41 & 1.32 & 1.39 & \multirow{4}{*}{146} & \multirow{4}{*}{0.92} \\
\hline & C50F0 & 137 & 102.09 & 91.57 & 1.34 & 1.50 & & \\
\hline & C60F0 & 134 & 99.60 & 83.60 & 1.35 & 1.60 & & \\
\hline & C80F0 & 132 & 94.29 & 67.12 & 1.40 & 1.97 & & \\
\hline & & & & Mean & 1.34 & 1.51 & & \\
\hline & & & \multicolumn{2}{|c|}{ Standard deviation } & 0.05 & 0.31 & & \\
\hline \multirow{6}{*}{ PS-2 } & Ox37 & 143 & 94.29 & 67.12 & 1.52 & 2.13 & & \\
\hline & Ox50 & 141 & 94.29 & 67.12 & 1.50 & 2.10 & & \\
\hline & Ox75 & 137 & 94.29 & 67.12 & 1.45 & 2.04 & & \\
\hline & Ox100 & 132 & 94.29 & 67.12 & 1.40 & 1.97 & & \\
\hline & & & & Mean & 1.47 & 2.06 & & \\
\hline & & & \multicolumn{2}{|c|}{ Standard deviation } & 0.05 & 0.07 & & \\
\hline \multirow{6}{*}{ PS-3 } & Oy37 & 144 & 106.78 & 107.14 & 1.35 & 1.34 & & \\
\hline & Oy50 & 140 & 104.48 & 99.41 & 1.34 & 1.41 & & \\
\hline & Oy75 & 138 & 99.60 & 83.60 & 1.39 & 1.65 & & \\
\hline & Oy100 & 132 & 94.29 & 67.12 & 1.40 & 1.97 & & \\
\hline & & & & Mean & 1.37 & 1.59 & & \\
\hline & & & \multicolumn{2}{|c|}{ Standard deviation } & 0.03 & 0.28 & & \\
\hline \multirow{6}{*}{ PS-4 } & C80F0 & 132 & 94.29 & 67.12 & 1.40 & 1.97 & & \\
\hline & C80F1 & 136 & 102.94 & 94.32 & 1.32 & 1.44 & & \\
\hline & C80F2 & 138 & 106.15 & 105.00 & 1.30 & 1.31 & & \\
\hline & C80F3 & 141 & 107.82 & 110.73 & 1.31 & 1.27 & & \\
\hline & & & & Mean & 1.33 & 1.50 & & \\
\hline & & & Standar & eviation & 0.05 & 0.32 & & \\
\hline \multirow{7}{*}{ PS-5 } & Cx30 & 127 & 74.64 & 43.13 & 1.70 & 2.94 & & \\
\hline & Cx60 & 128 & 87.95 & 61.56 & 1.46 & 2.08 & & \\
\hline & Cx80 & 128 & 95.83 & 76.78 & 1.34 & 1.67 & & \\
\hline & Cx100 & 136 & 102.94 & 94.32 & 1.32 & 1.44 & & \\
\hline & & & & Mean & 1.46 & 2.03 & & \\
\hline & & & \multicolumn{2}{|c|}{ Standard deviation } & 0.17 & 0.66 & & \\
\hline & Су30 & 123 & 89.04 & 57.31 & 1.38 & 2.15 & & \\
\hline
\end{tabular}




\begin{tabular}{lcccccc} 
PS-6 & Cy60 & 126 & 95.38 & 75.01 & 1.32 & 1.68 \\
& Cy80 & 128 & 99.28 & 85.13 & 1.29 & 1.50 \\
& Cy100 & 129 & 102.94 & 94.32 & 1.25 & 1.37 \\
\hline & & & Mean & 1.31 & 1.67 \\
& & & Standard deviation & 0.05 & 0.34 \\
\hline
\end{tabular}




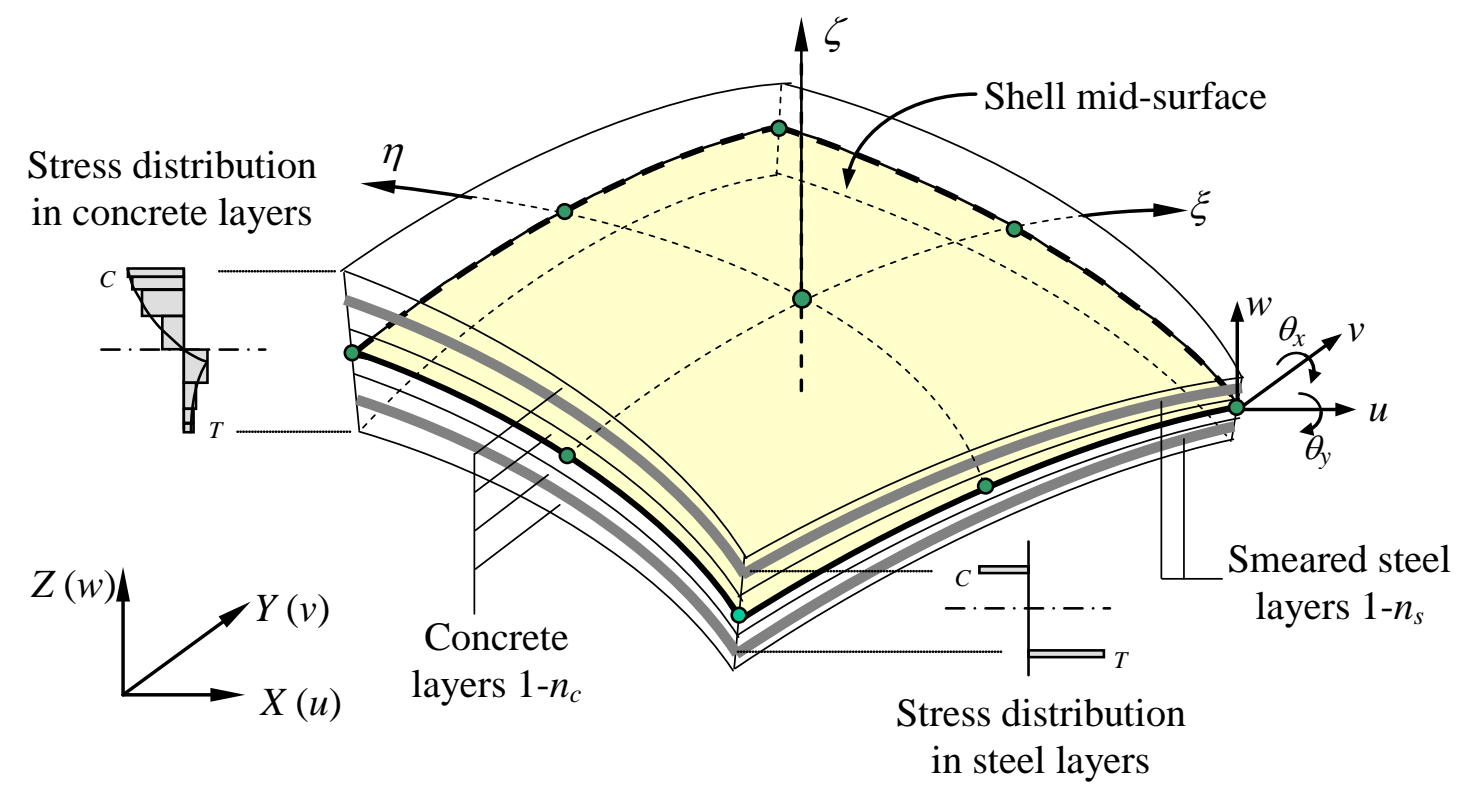

Figure 1. 8-node degenerate shell element with concrete and steel layers 


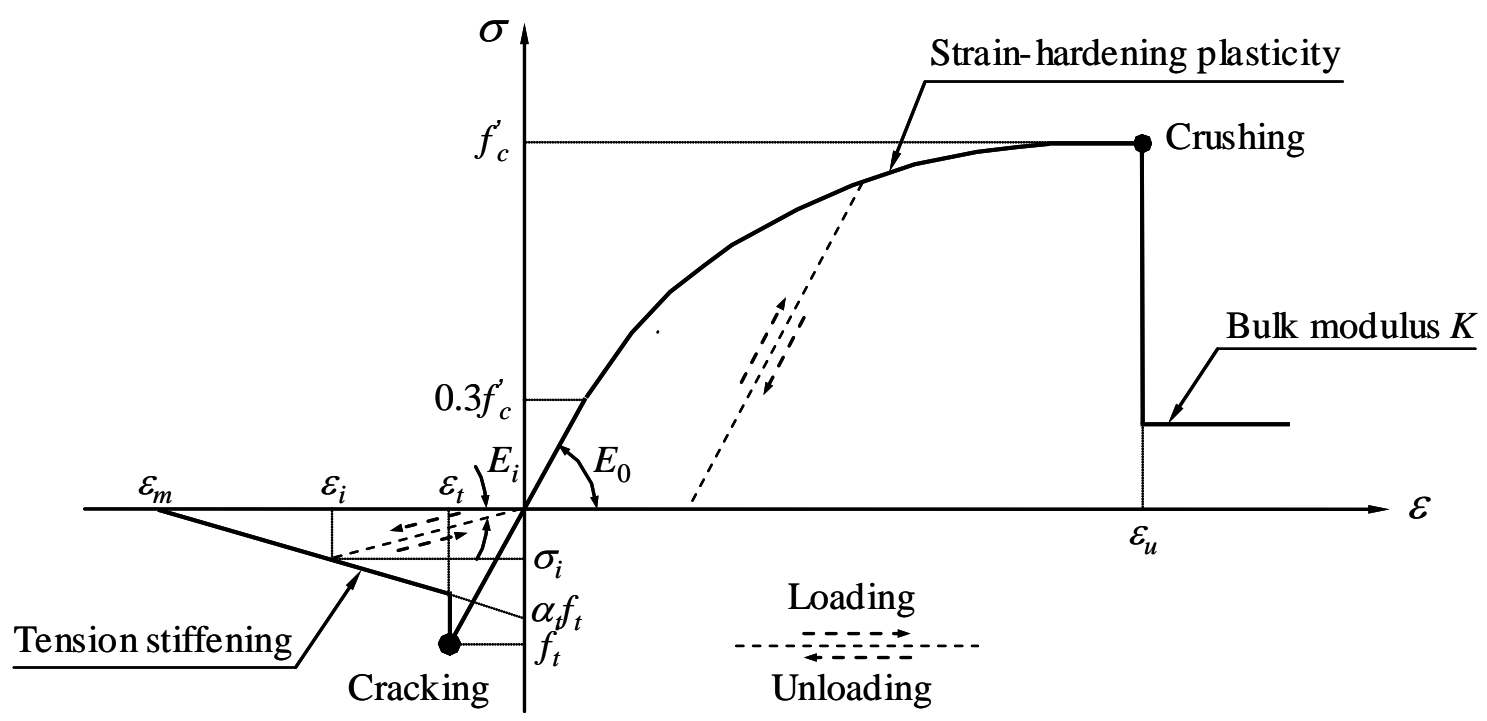

(a) concrete in compression and tension (one-dimensional representation)

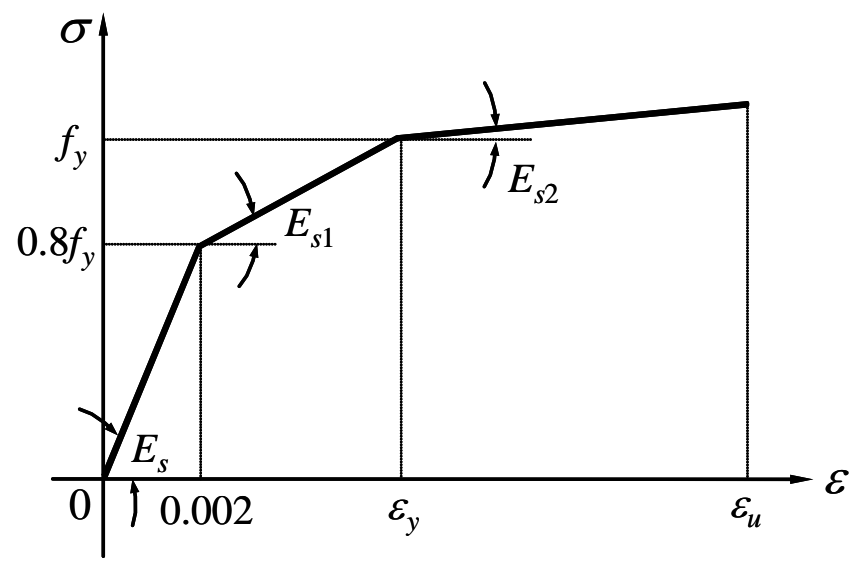

(b) steel

Figure 2. Material constitutive model 


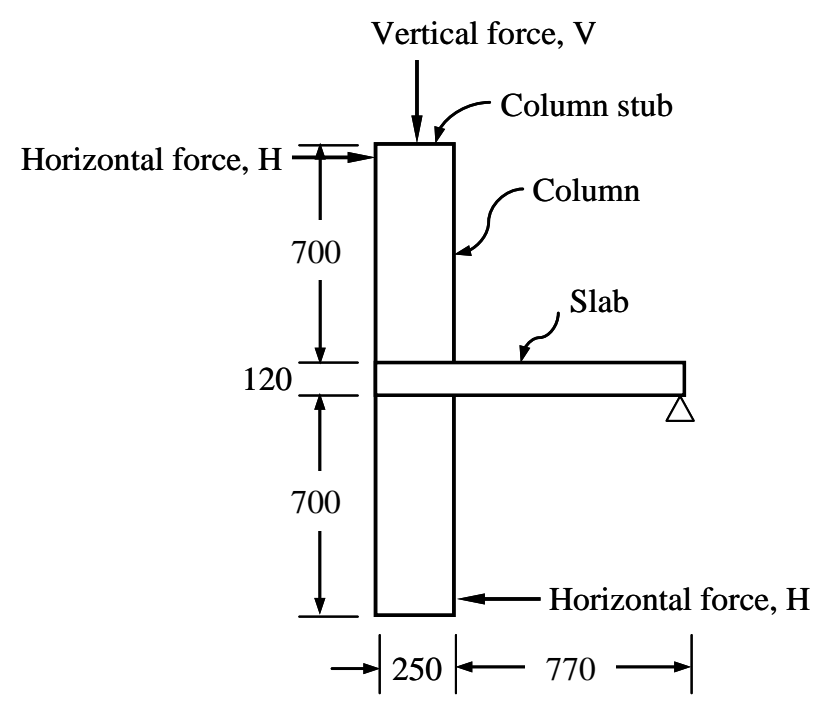

(a) elevation

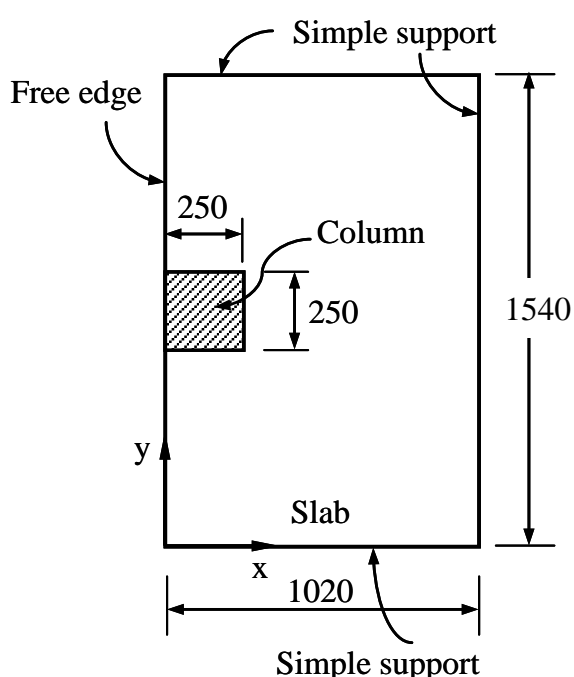

(b) plan view

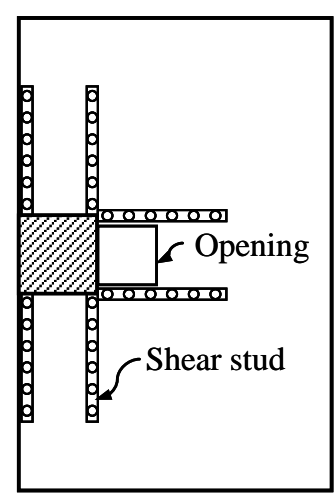

(c) connection with shear stud and opening

Figure 3. Typical slab-column connection model (dimensions in mm) 

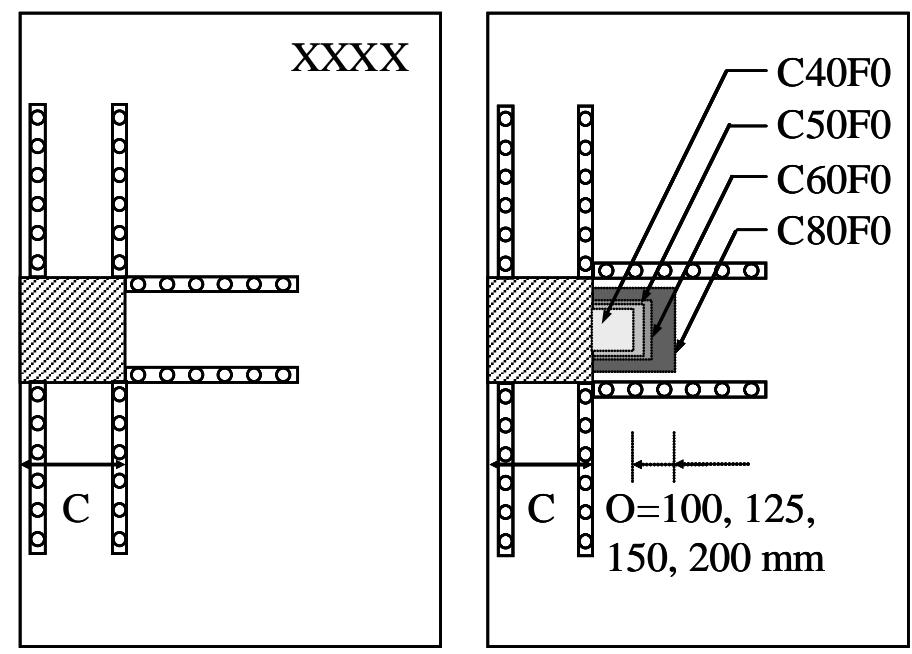

(a) Control model and PS-1: varying opening size (both $x$ - and $y$-directions)
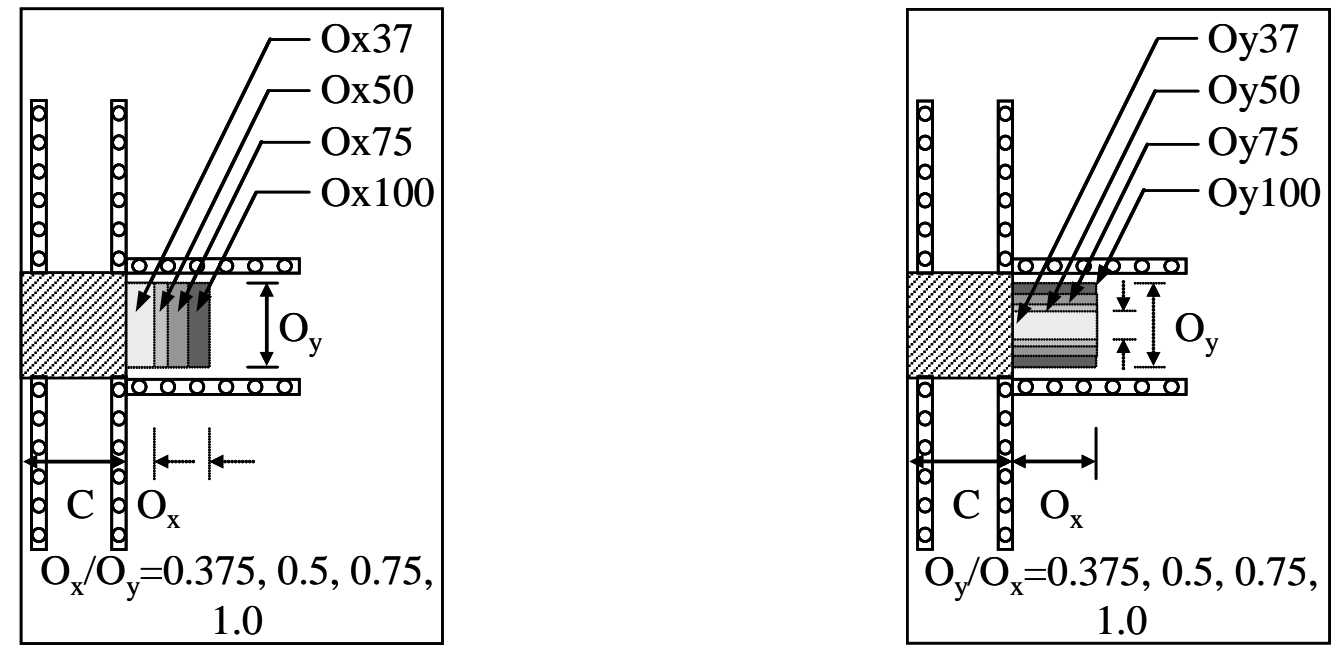

(b) PS-2: varying opening aspect ratio ( $x$-direction) (c) PS-3: varying opening aspect ratio ( $y$-direction)

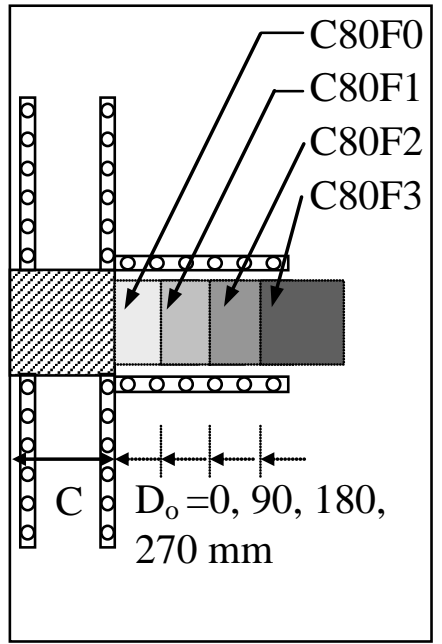

(d) PS-4: varying opening location from front face of column 


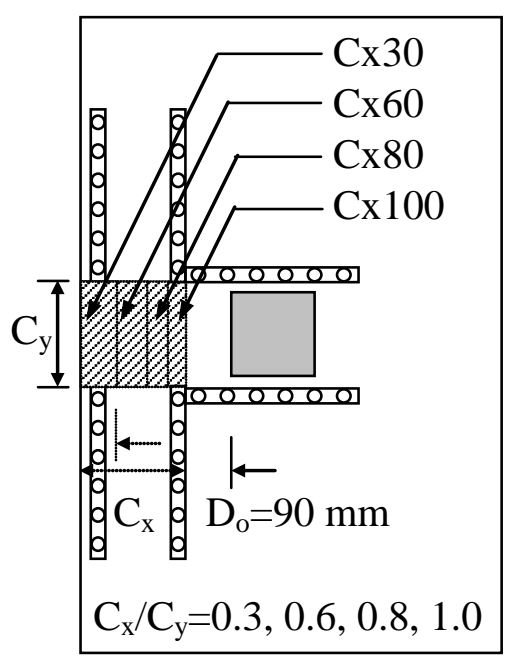

(e) PS-5: varying column aspect ratio ( $x$-direction)

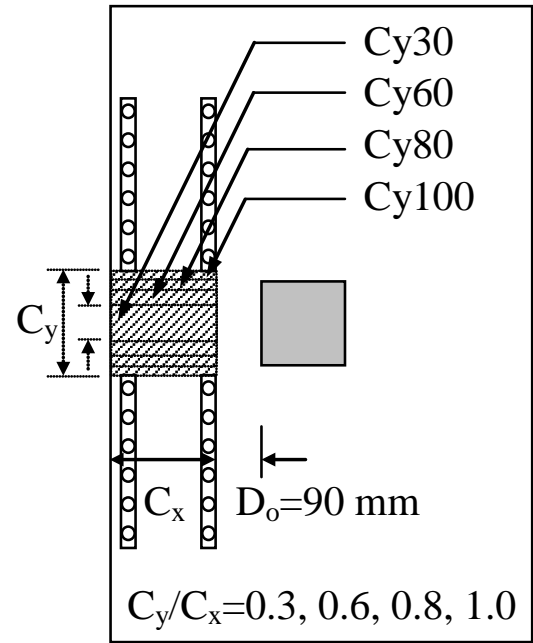

(f) PS-6: varying column aspect ratio (y-direction)

Figure 4. Model layout for parametric studies (PS) 


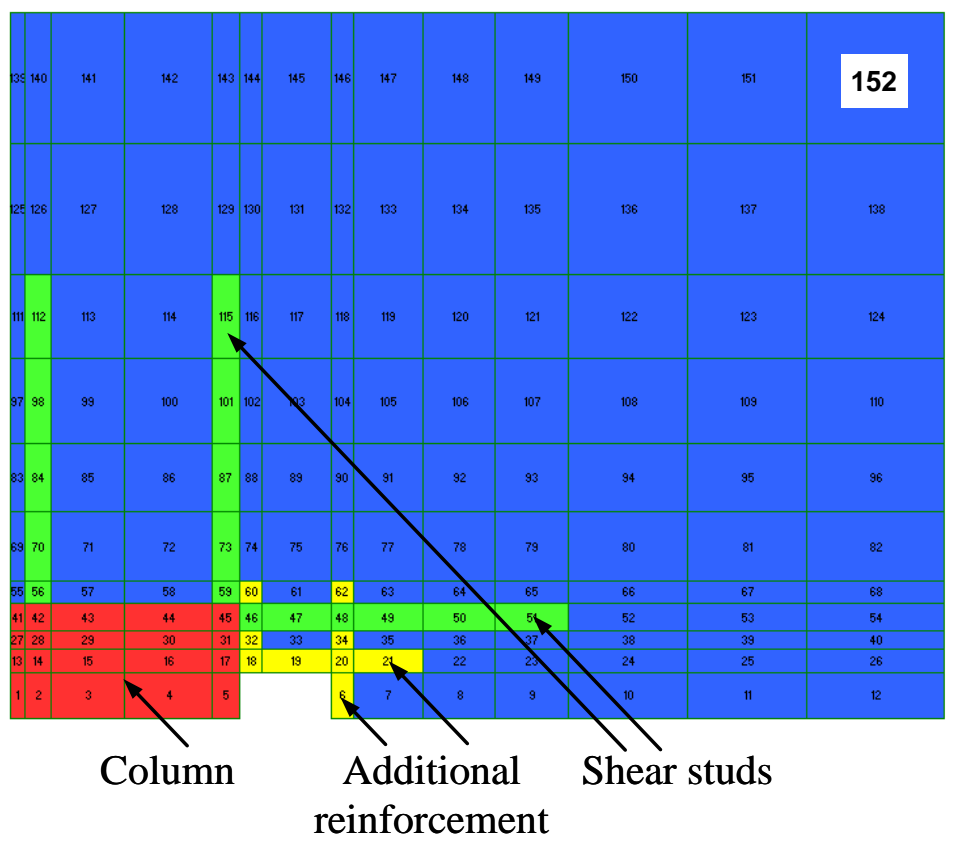

(a) $\mathrm{C} 40 \mathrm{~F} 0$

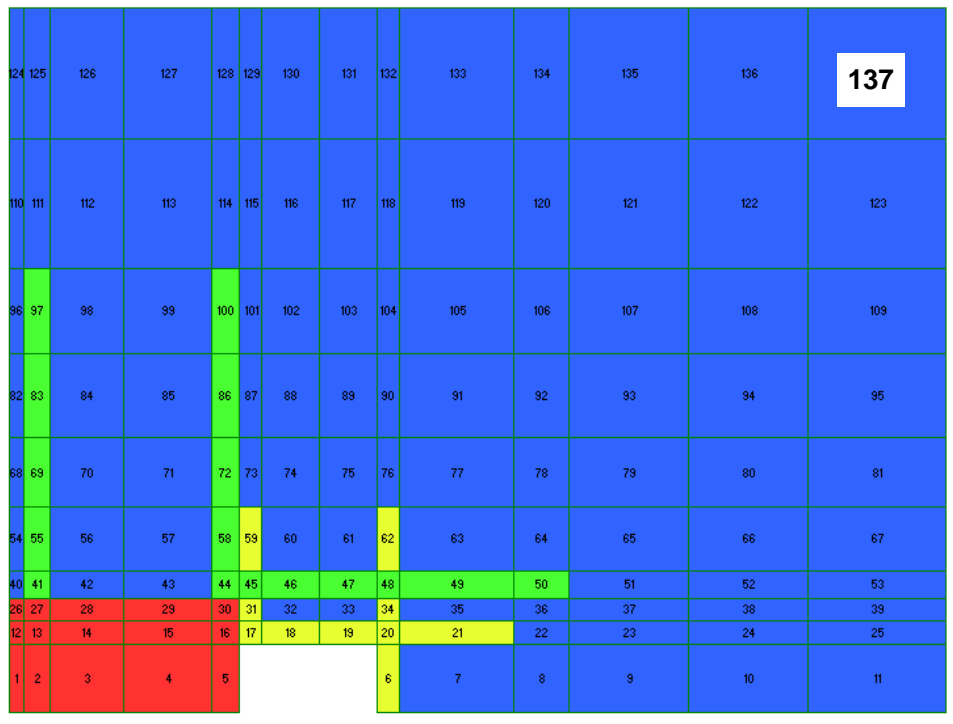

(b) $\mathrm{C} 60 \mathrm{~F} 0$

Figure 5. Mesh design for models in PS-1 


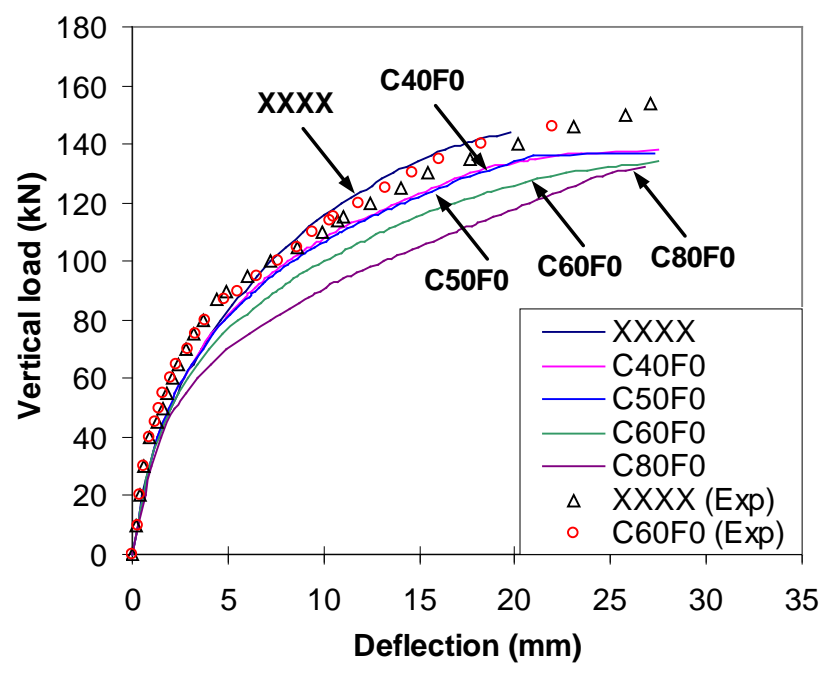

(a) load-deflection response

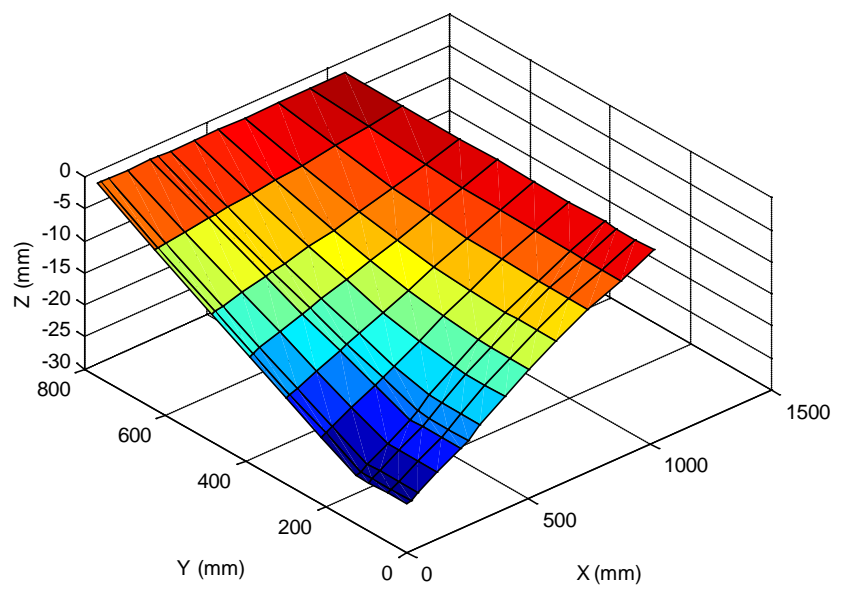

(b1) XXXX

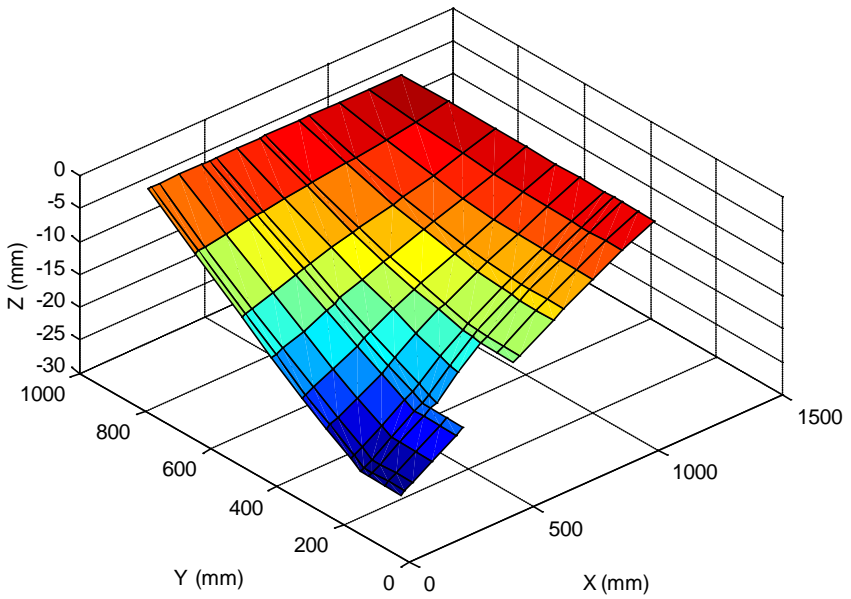

(b2) $\mathrm{C} 80 \mathrm{~F} 0$

(b) deflected shape (XXXX and C80F0) 


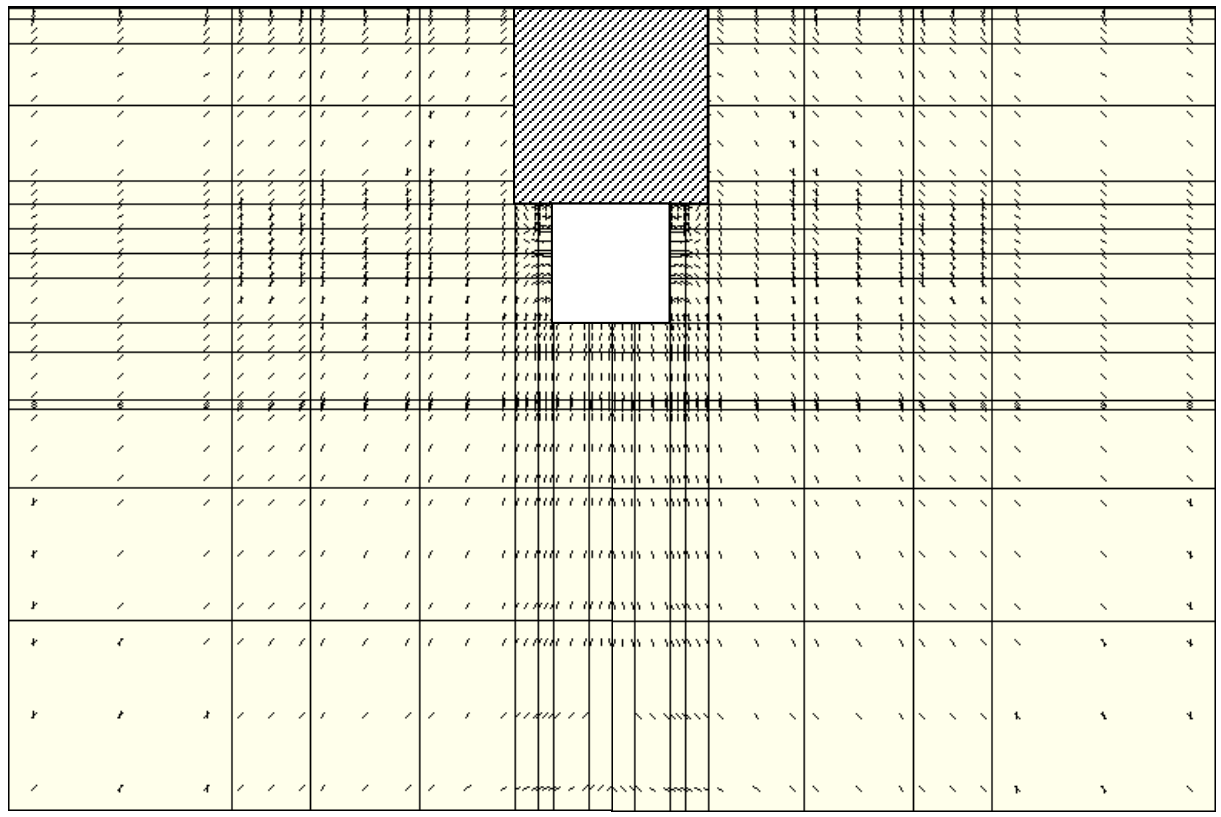

(c1) predicted

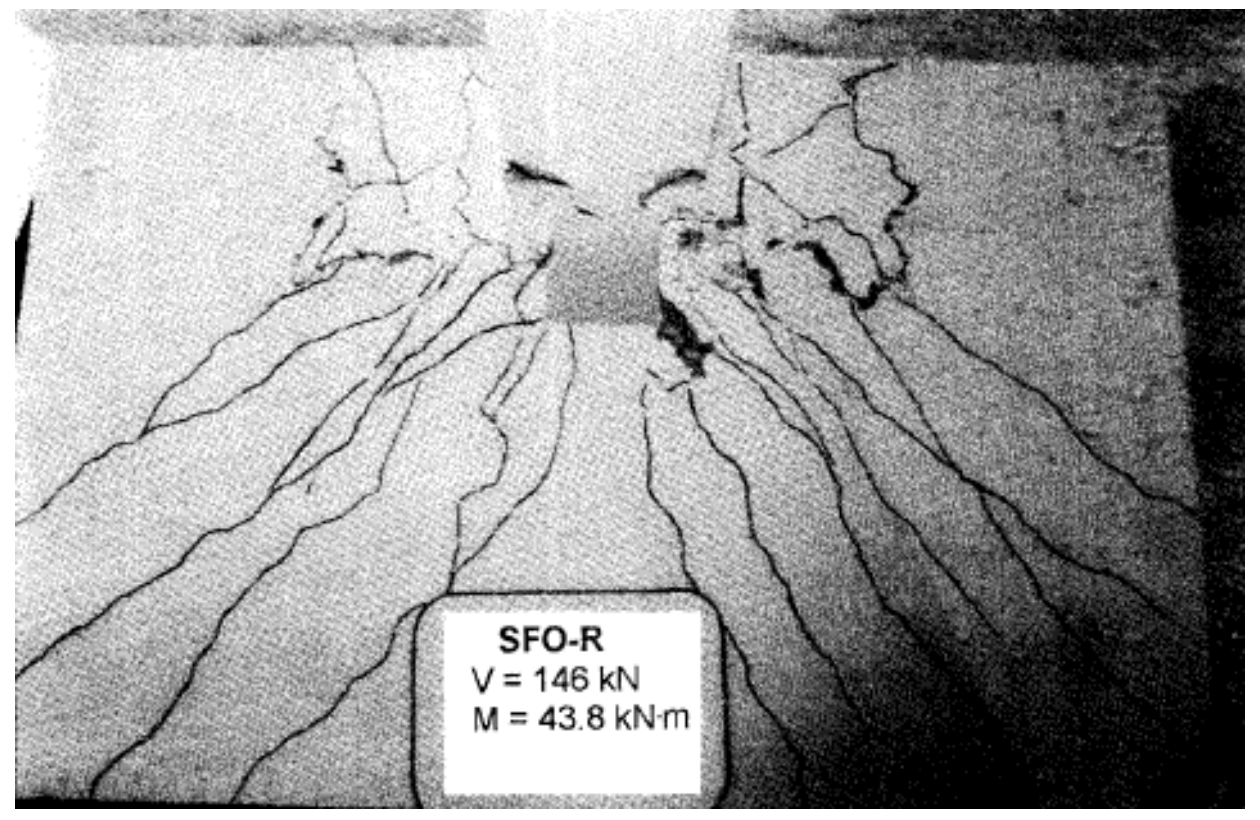

(c2) experiment (equivalent to C60F0)

(c) crack pattern (C60F0)

Figure 6. Failure characteristics of models in PS-1 


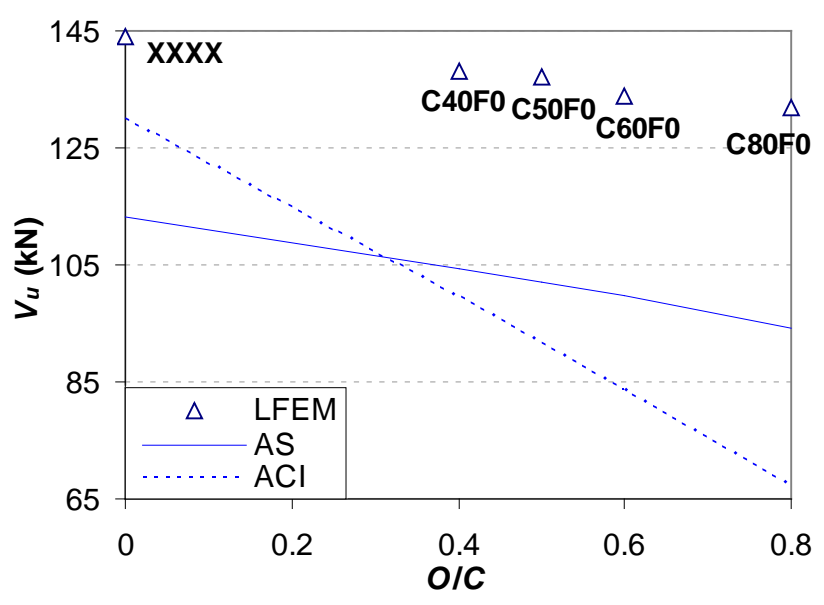

(a) PS-1

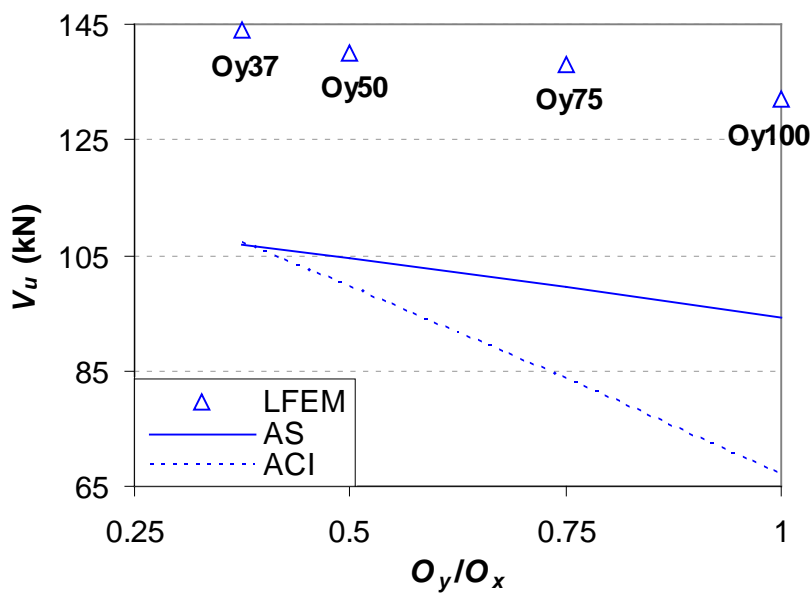

(c) PS-3

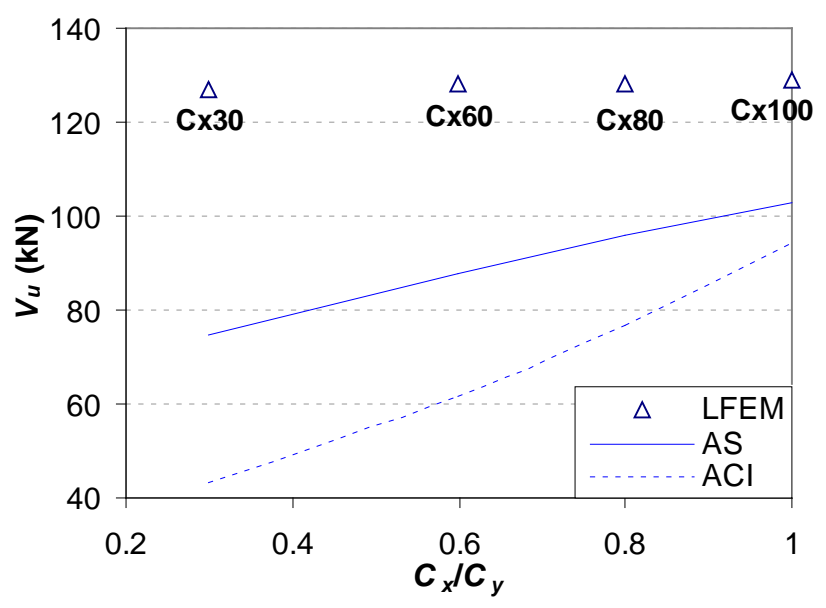

(e) PS-5

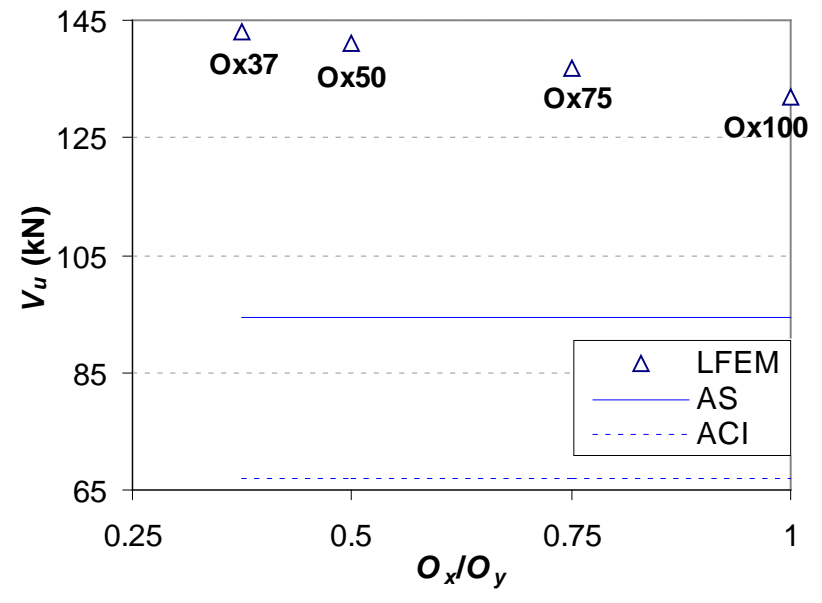

(b) PS-2

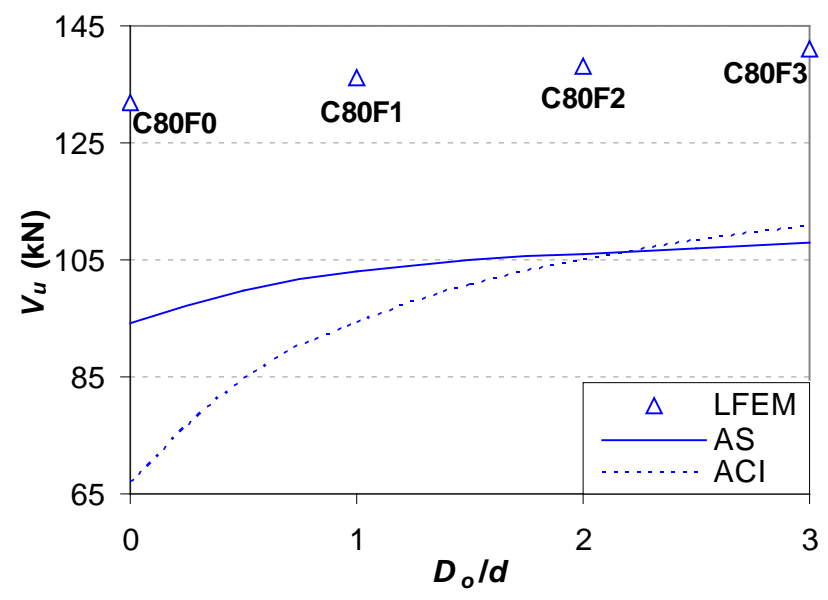

(d) PS-4

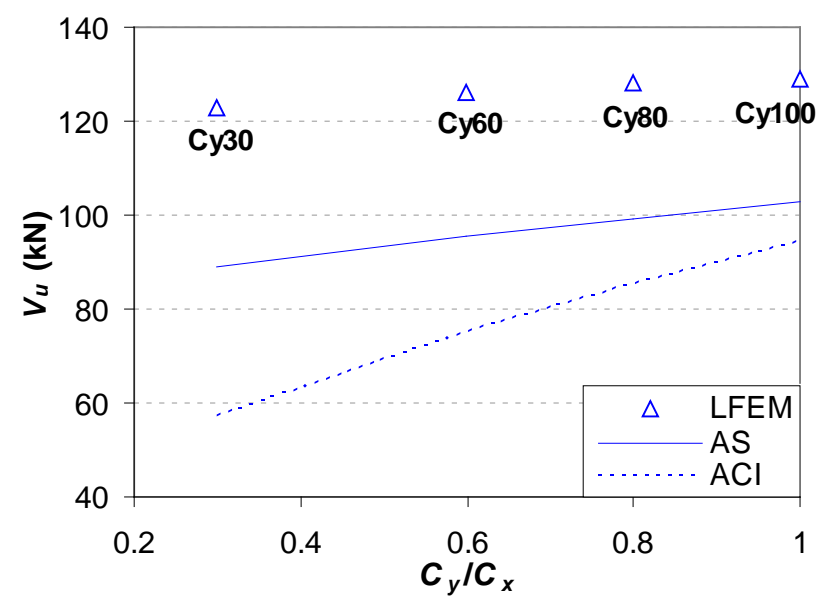

(f) PS-6

Figure 7. Effect of varying parameters on $V_{u}(\mathrm{kN})$ 

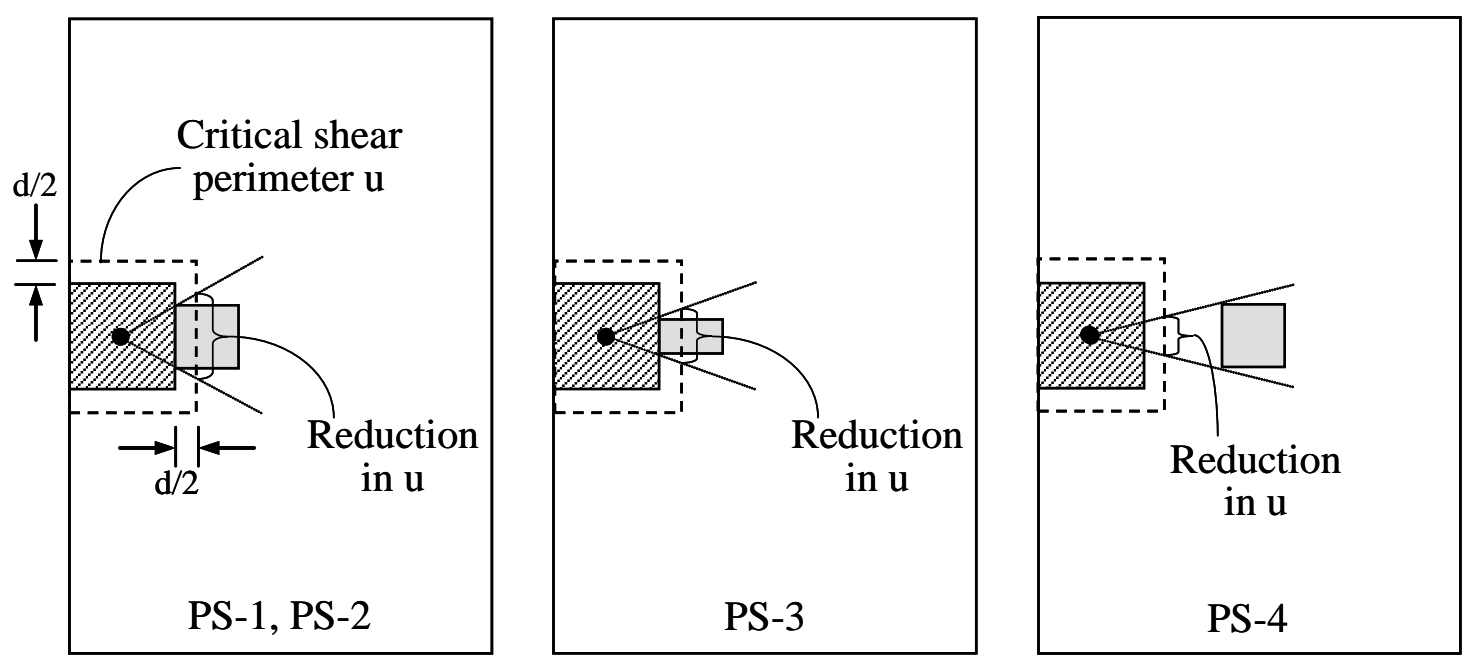

(a) varying opening size and location
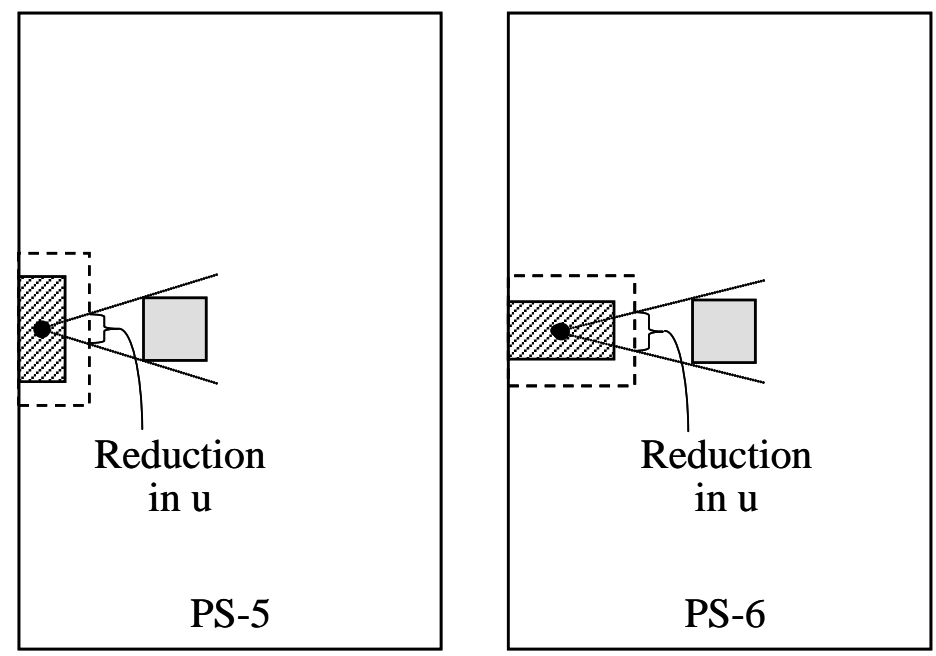

(b) varying column size

Figure 8. Critical shear perimeter used in AS3600 and ACI318 